\title{
Observation and Modeling of Energetic Particles at Synchronous Orbit on July 29, 1977
}

\author{
D. N. BAKER and P. R. HIGBIE \\ Los Alamos National Laboratory, Los Alamos, N. Mex. 87545; \\ T. A. FRITZ \\ Space Environment Laboratory, NOAA, Boulder, Colo. 80302; \\ B. WILKEN \\ Max-Planck-Institut für Aeronomie, Katlenburg-Lindau, F.R.G.; \\ S. M. KAYE \\ Lockheed Palo Alto Research Laboratory, Palo Alto, Calif. 94304; \\ M. G. KIVELSON \\ University of California, Los Angeles, Calif. 90025; \\ T. E. MOORE \\ University of New Hampshire, Durham, N. Hamp. 03824; \\ A. J. MASLEY \\ TRW Systems, Redondo Beach, Calif. 90278; \\ P. H. SMITH \\ Goddard Space Flight Center, Greenbelt, Md. 20771; \\ A. L. VAMPOLA \\ Space Sciences Laboratory \\ The Aerospace Corporation, El Segundo, Calif. 90245
}

16 August 1982

APPROVED FOR PUBLIC RELEASE;

DISTRIBUTION UNLIMITED

Prepared for

SPACE DIVISION

AIR FORCE SYSTEMS COMMAND

Los Angeles Air Force Station

P.O. Box 92960, Worldway Postal Center

Los Angeles, California 90009

\section{LIDRARY RAPY}

RITT 121982

LANGLEY RESEARCH CENTER LIERARY, NASA HAMIPTON, VIRGINIA 
This report was submitted by The Aerospace Corporation, El Segundo, CA 90245, under Contract No. F04701-81-C-0082 with the Space Division, Deputy for Technology, P. 0. Box 92960, Worldway Postal Center, Los Angeles, CA 90009. It was reviewed and approved for The Aerospace Corporation by H. R. Rugge, Director, Space Sciences Laboratory. Lt Randa11 S. Weidenheimer, SD/YLVS, was the project officer for Mission-Oriented Investigation and Experimentation (MOIE) Programs.

This report has been reviewed by the Public Affairs office (PAS) and is releasable to the National Technical Information Service (NTIS). At NTIS, 1 t w111 be avallable to the general public, Including foreign nations.

This technical report has been reviewed and is approved for publication. Publication of this report does not constitute Air Force approval of the report's findings or conclusions. It is published only for the exchange and stimulation of ideas.

Rordall derit Wrideibeinel Randa11 S. Veidenheimer, 2nd Lt, USAF Project officer

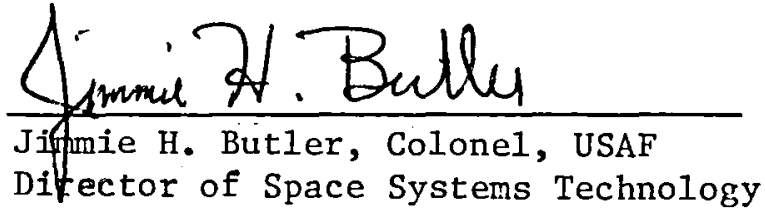

FOR THE COMMANDER

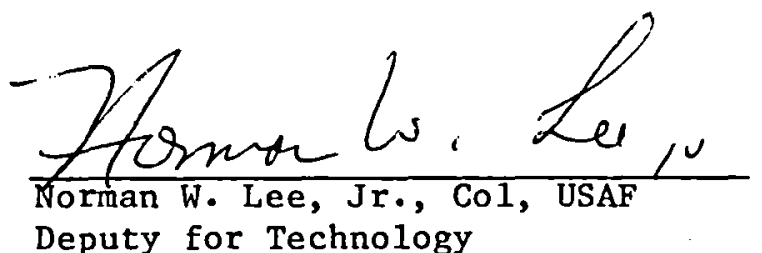




\begin{tabular}{|c|c|}
\hline REPORT DOCUMENTATION PAGE & $\begin{array}{l}\text { READ INSTRUCTIONS } \\
\text { BEFORE COMPLETING FORM }\end{array}$ \\
\hline \begin{tabular}{l|l} 
1. REPORT NUMBER & 2. GOVT ACCESSION NO. \\
SD-TR- $82-56$ &
\end{tabular} & 3. RECIPIENT'S CATALOG NUMBER \\
\hline $\begin{array}{l}\text { 4. TITLE (and Substito) } \\
\text { OBSERVATION AND MODELING OF ENERGETIC } \\
\text { PARTICLES AT SYNCHRONOUS ORBIT ON } \\
\text { JULY } 29,1977\end{array}$ & $\begin{array}{l}\text { 6. PERFORMING ORG. REPORT NUMBER } \\
\text { TR-0082 (2940-05) }-7\end{array}$ \\
\hline $\begin{array}{l}\text { 7. AUTHOR(a) } \\
\text { Alfred L. Vampola, et al. }\end{array}$ & $\begin{array}{l}\text { 8. CONTRACT OR GRANT NUMBER(A) } \\
\text { F04701-81-C-0082 }\end{array}$ \\
\hline $\begin{array}{l}\text { 9. PERFORMING ORGANIZATION NAME AND ADDRESS } \\
\text { The Aerospace Corporation } \\
\text { E1 Segundo, Calif. } 90245\end{array}$ & $\begin{array}{l}\text { 10. PROGRAMELEMEET, PROJECT, TASK } \\
\text { AREA Q WORK UNIT'NUMBERS }\end{array}$ \\
\hline $\begin{array}{l}\text { 11. CONTROLLING OfFICE NAME AND ADDRESS } \\
\text { Space Division } \\
\text { Los Angeles Air Force Station } \\
\text { Los Angeles, Calif. } 90009 \\
\end{array}$ & $\begin{array}{l}\text { 12. REPORT DATE } \\
16 \text { AuguSt } 1982 \\
\text { 13. NUMBER OF PAGES } \\
54 \\
\end{array}$ \\
\hline 14. MONITORING AGENCY NAME A ADDRESS(II dillofont from Controlline Othlico) & $\begin{array}{l}\text { 15. SECURITY CLASS. (of thie roport) } \\
\text { UnClaSSIfIEd } \\
\text { 15. DECLASSIIICATION/OOWNGRADING } \\
\text { SCHEDULE }\end{array}$ \\
\hline
\end{tabular}

16. DISTRIBUTION STATEMENT (OI thle ROPORt)

Approved for public release; distribution unlimited

17. DISTRIBUTION STATEMENT (ot the abetract onfered in Block 20, 1 different froon Roport)

18. SUPPLEMENTARY NOTES

19. KEY WORDS (Continue on roverse aldo If necessary and Idontily by block number)

Magnetospheric particles

Magnetospheric substorm effects

Synchronous orbit environment

20. ABSTRACT (ContInue on roverce side II noceseary and Identlty by block number)

In the twelve hours following a worldwide storm sudden commencement at 0027 UT on $29 \mathrm{July}$, there was a series of at least four magnetospheric substorms, the last and largest of which exhibited an expansion phase onset at 1200 UT. Data from six spacecraft in three general local time groupings (0300, 0700, and $1300 \mathrm{LT}$ ) were examined and vector magnetic field data and energetic electron and ion data from $\sim 15 \mathrm{keV}$ to $>2 \mathrm{MeV}$ were employed. Four primary types of studies were carried out: (1) Timing and morphology of energetic particle injections; (2) Variation of particle phase space densities, $f\left(\mu=p^{2} / 2 \mathrm{mB}\right)$ 
using local magnetic field and particle flux data; (3) Measurement of boundary motions using high-energy ion gradient anisotropies; and (4). Adiabatic modeling which included injection, large-scale convection, corotation, and gradient drifts. For the 1200 UT substorm, it is concluded that there was a substantial flux dropout in a broad sector near local midnight due to a largescale boundary motion followed by a recovery to a predropout configuration. There were then several subsequent injection events with distinct ansets (extending as far eastward as $0300 \mathrm{LT}$ ) for which ion anisotropy information suggests an inward motion of particles from outside of geostationary orbit. Particle drift information reveals that these particles drifted azimuthally completely around the earth. It is also concluded from the phase space density studies that "fresh" particles with magnetic moments up to at least several hundred MeV/gauss were injected near geostationary orbit. The present adiabatic dipolar convection model can explain the observed injection of large magnetic moment particles from the plasma sheet into synchronous orbit, although physical elements of the normal model must be altered somewhat. 
This report was prepared by D. N. Baker, P. R. Higbie, Los Alamos National Laboratory, Los Alamos, N. Mex.; T. A. Fritz, Space Environment Laboratory, NOAA, Boulder, Colo.; B. Wilken, Max-Planck-Institut fur Aeronomie, Katlenburg-Lindau, Federal Republic of Germany; S. M. Kaye, Lockheed Palo Alto Research Laboratory, Palo Alto, Calif.; M. G. Kivelson, University of California, Los Angeles, Calif.; T. E. Moore, University of New Hampshire, Durham, N. Hamp.; A. J. Masley, TRW Systems, Redondo Beach, Cal1f.; P. H. Smith, Goddard Space Flight Center, Greenbelt, Md.; A. L. Vampola, Space Sciences Laboratory, The Aerospace Corp.

A major portion of this work was presented at the SCOSTEP/IAGA Symposium on the International Magnetospheric Study, La Trobe University, Melbourne, Austral1a, November 1979. The authors thank E. W. Hones, Jr., R. D. Bellan, R. L. McPherron, and J. T. Gosling for useful comments and suggestions on this paper. Work at Los Alamos was done under the auspices of the U.S. Department of Energy. Work at UCLA was supported by National Science Foundation grant ATM-7923586. 


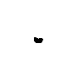


CONTENTS

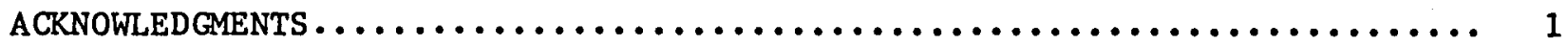

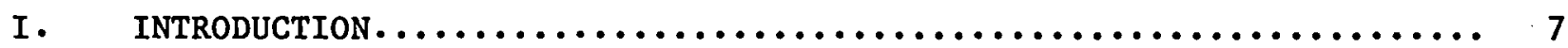

II. OBSERVATIONS .................................... 10

Energetic Particle Behavior at 0300 LT...................... 13

Energetic Particle Behavior at 0700 LT.................... 17

Energetic Particle Behavior at $1300 \mathrm{LT} \ldots \ldots \ldots \ldots \ldots \ldots \ldots \ldots \ldots \ldots \ldots$

Phase Space Density Variations......................... 22

Gradient Anisotropy Information....................... 31

Drift-Echo Timing Information........................ 39

Adlabatic Modeling Results........................... 43

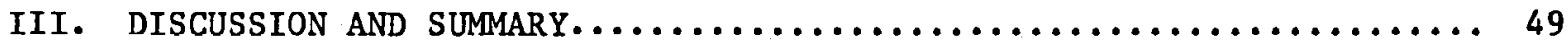

REFERENCES $\ldots \ldots \ldots \ldots \ldots \ldots \ldots \ldots \ldots \ldots \ldots \ldots \ldots \ldots \ldots \ldots \ldots \ldots \ldots \ldots \ldots \ldots \ldots \ldots \ldots$ 
.$$
\text { - }
$$

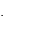


FIGURES

1. Positions of the Geostationary and Near-Geostationary (GEOS-1)

Spacecraft Used in This Study............................ 11

2. Common Scale Magnetograms and AE Indices for July 28-30, 1977...... 12

3. Representative Differential Energetic Electron Flux Profiles for the Period 1130-1300 UT on 29 July 1977 at the $0300 \mathrm{LT}$

Spacecraft Position............................... 14

4. Representative Differential Energetic Proton Flux Profiles for the Period 1130-1300 UT on 29 July 1977 at the $0300 \mathrm{LT}$ Space-

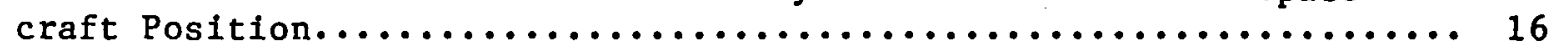

5. High-Energy Proton Data at the 0300 LT Spacecraft Position for

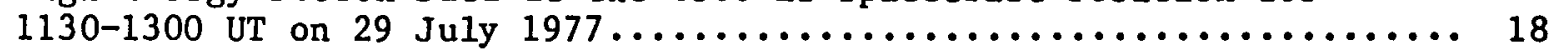

6. Same as Figure 3 for the 0700 LT Spacecraft Position............ 19

7. Same as Figure 5 for the $0700 \mathrm{LT}$ Spacecraft Position............ 21

8. GEOS-1 (1300 LT) Energetic Electron Stacked-Spectrum Data for

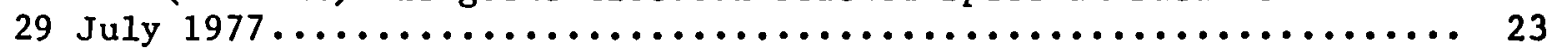

9. GEOS-1 (1300 LT) Energetic Proton Stacked-Spectrum Data for

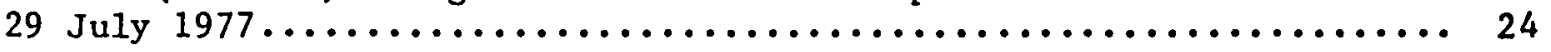

10. Differential Energy Spectra for Electrons and Protons at the UT's Indicated Near Each Data Set......................... 26

11. Total Magnetic Field Strength Variations for the 1200 UT Substorm at the 0300 and 0700 LT Grouping Positions Studied in this Paper............................... 28

12. Electron Phase Space Density Variations for the 1200 UT Substorm Period................................... 30

13. Proton Phase Space Density Variations for the 1200 UT Substorm Period..........................................

14. Field Line Dipolar Tilt Angle, $\theta_{B}$, Inferred from the Energetic Electron Anisotropy Symmetry Axis................. 36

15. Proton ( $E_{p}>145 \mathrm{keV}$ ) Gradient Anisotropy Data for the Period

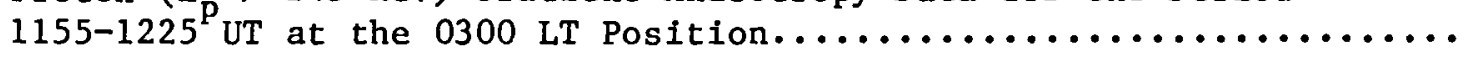




\section{FIGURES (Continued)}

16. A Comparison of the $>145 \mathrm{keV}$ Proton Flux and the Associated East-West Gradient Anisotropy........................... 40

17. High Time Resolution Plot for the $0.4-0.5 \mathrm{MeV}$ Proton Channel

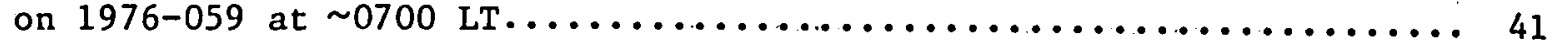

18. Local Time (' $\phi$ ') Versus UT Plots for High-Energy Drift-Echo Pulses Seen at S/C 1977-007 and 1976-059................... 44

19. Several Time-Dependent Convection Model Trajectory Plots for High-Energy Protons on July $29,1977 \ldots \ldots \ldots \ldots \ldots \ldots \ldots \ldots \ldots \ldots \ldots$

\section{TABLES}

1. Proton Gradient Anisotropy Information.................... 35

2. Proton Drift-Echo Pulse Time.......................... 42 


\section{Introduction}

During the past two decades, space physics has progressed from missions whose goal was a rudimentary exploration of the near-earth magnetosphere to the present stage in wich rather detailed modeling and understanding of magnetospheric plasma processes has emerged. Nonetheless, because of the vast scale distances involved within the magnetosphere, it has been a very difficult problem to probe the system, concurrently, at enough different points to truly understand the complex relationships between 1 ts different parts.

Understanding just the 'quiet' or 'equilibrium' state of the magnetosphere has been a challenge. Even more difficult has been the problem of understanding the dynamic behavior of the magnetosphere. This dynamic aspect of the magnetosphere may be effectively discussed in terms of energy input from the solar wind into the magnetosphere. Such excess added energy causes the magnetospheric system to move out of its equilibrium state into a more energetic state. In same cases this gives rise to a very large scale disturbance (the geomagnetic storm) which in turn causes worldwide effects. Much more frequently, however, disturbances within the magnetosphere tend to be somewhat more localized involving the regions connecting to nightside auroral field IInes: such a disturbance is termed the magnetospheric substorm. (See the paper by McPherron [1973, and papers thereafter] for a discussion of a phenomenological model of substorms.)

In order to understand better the nonequilibrium behavior of the magnetosphere, a period (July 28-30, 1977) was chosen for intensive study. 
This period was characterized by the development of a large geomagnetic storm and al so by the occurrence of several magnetospheric substorms [Manka et al.. 1981]. In addition this period offered the advantage that there. were a total of 12 earth-orbiting spacecraft positioned at widely separated points immediately upstream and throughout the magnetosphere and these satellites provided data coverage of plasma and field changes associated with the geom agnetic storm and substorms.

In order to exploit fully the information provided by such a wide array of spacecraft probes, an effort was made under the aegis of the International Magnetospheric Study (IMS), to assemble researchers who had data from satellites for the 28-30 July 1977 time period. In May of 1979, approximately 10 scientists with interest in, and data on, the high-energy plasmas of the magnetosphere met at the National Space Science Data Center (NSSDC) located at the NASA Goddard Space Fight Center in Greenbelt, Maryland. In a workshop setting called CDAW 2.0 (Coordinated Data Analysis Workshop - 2), the researchers studied data which they had earlier provided to a central computer facility. This central computer allowed data from any sensor on any satellite to be directly campared with concurrently-acquired data from any other sensor on the same or any other satellite. Thus, unlike most prior space research situations, experimenters, modelers, and theorists had at their immediate command the data required to address many questions about magnetospheric dynamics. Variations of plasma conditions throughout much of the magnetosphere could thus be described for a large number of different regions. There are two distinct facets of, or reasons for studying, energetic 
particles within the earth's magnetosphere. The first of these facets reflects the intrinsically interesting question of where, and how, these particles are actually produced, say, during magnetospheric substorms. The second facet of energetic particle studies is a very practical and pragmatic one: given that such particles exist (i.e., that they can be observed) how can these particles be used as tracers or probes of large-scale magnetospheric processes? The CDAW-2 subgroup 6 research team attempted to explore each of these avenues associated with energetic particles.

The types of studies carried out by subgroup 6 were basically four in number :

(1) Timing and morphology of particle injections;

(2) Variation of particle phase space densities:

(3) Measurement of boundary motions using ion (proton) gradient anisotropies; and

(4) Adiabatic modeling (with increased particle flux (1.e.. infection), convection, corotation, and drifts).

In the following, we will discuss our findings derived from each of the above lines of inquiry. Our initial research efforts were concentrated on the 1200 UT substorm of $29 \mathrm{July}$. This was the last and largest (AE $\sim 1200 \mathrm{Y}$ ) of a series of substorms that occurred on 29 July following a worldwide SSC that occurred at 0027 UT [King et al., 1981; Wilken et al., 1981]]. We concentrate here on measurements made at geostationary orbit $\left(6.6 R_{E}\right)$ where a total of $s i x$ spacecraft made extensive observations of the energetic particle behavior. 


\section{Observations}

Figure 1 is a geocentric solar ecliptic projection of the positions of the six primary, near-geostationary satellites used in the present study. The ATS-6 and 1977-007 spacecraft were located very near one another at $\sim 0300$ LT. ATS 6 had NOAA, Aerospace, and TRW energetic particle, UCLA magnetometer, and UNH plasma experiments on board, while 77-007 had Los Alamos energetic particle sensors on board. The Los Alamos-instrumented spacecraft 1976-059 at n0700 LT was bracketed by the GOES-1 and -2 satellites which carried NOAA energetic particle and magnetaneter instruments. Finally, the European Space Agency satellite GEOS-1 $\left(1.3 \leqslant r \leqslant 8 R_{E}\right)$ carried a complete complement of plasma and field measurement instruments and was located near apogee at $\sim 1300$ LT.

General geanagnetic activity for July 29-30, 1979 is shown in Figure 2 [see al so Manka et al., 1981]. The upper panel shows selected high-latitude magnetoneter station records, while the second panel from the top shows H-component magnetograms from five standard auroral zone stations. The third panel of Figure 2 shows mid-latitude stations from several geographic longltude sectors. The bottan panel summarizes auroral electrojet activity in the form of the $A E(5)$ index, 1.e.. the index derived from the five auroral zone stations shown in panel 2.

Particularly evident in Figure 2 are the storm sudden commencement (SSC), due to an interplanetary shock wave hitting the earth at 0027 UT on 29 July, [c.f. King et al., 1981 and W1lken et al., 1981] and the rapid storm mainphase development thereafter. These features are seen clearly in the midlatitude magnetograms of panel 3. Al so quite evident, especially in the plot of $A E$, are the generally disturbed auroral zone conditions on $29 \mathrm{July}$ and the large 


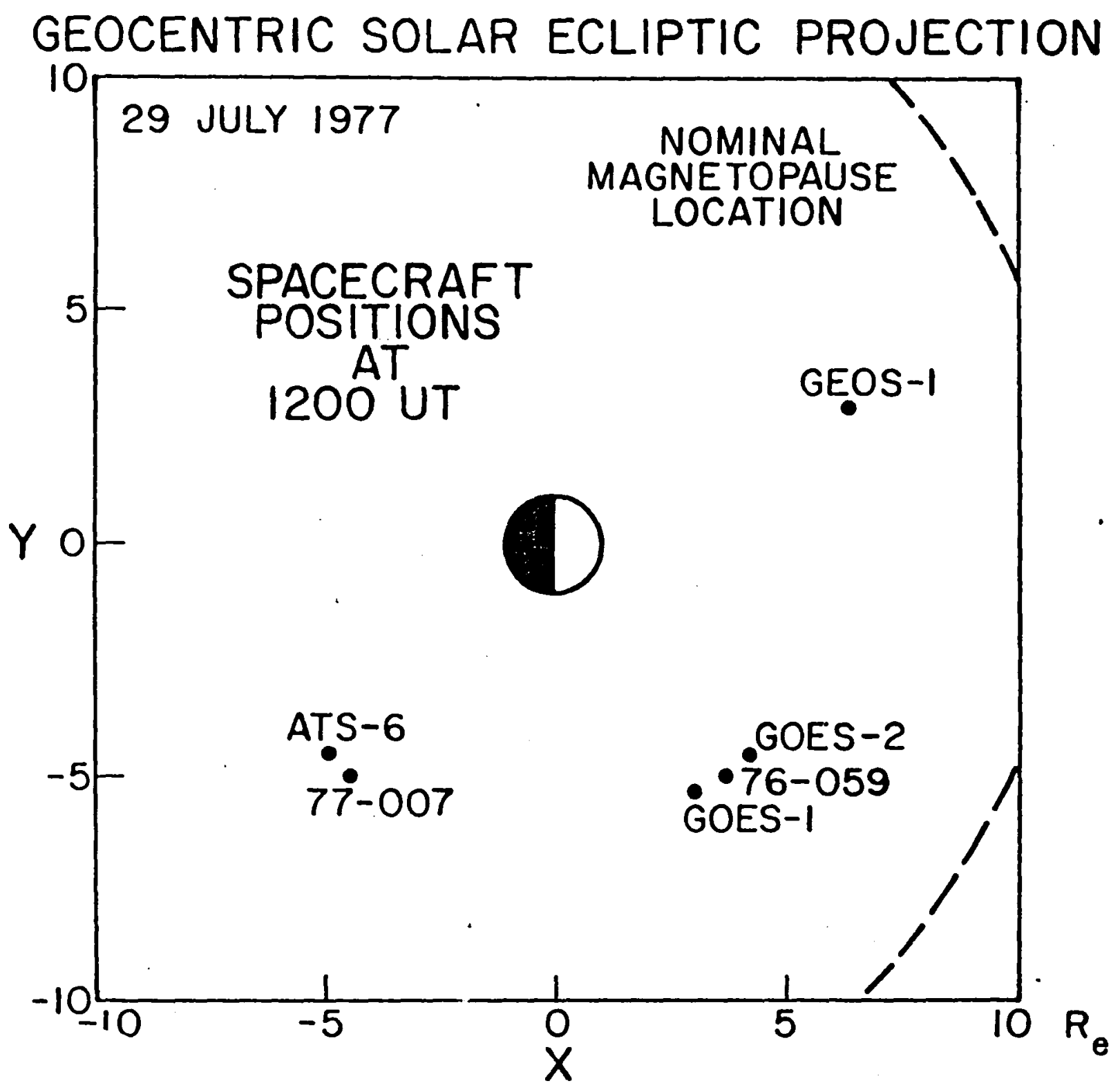

Fig. 1. Positions of the geostationary and near-geostationary (GEOS-1) spacecraft used in this study. The nominal magnetopause location in this solar ecliptic profection is also shown. 


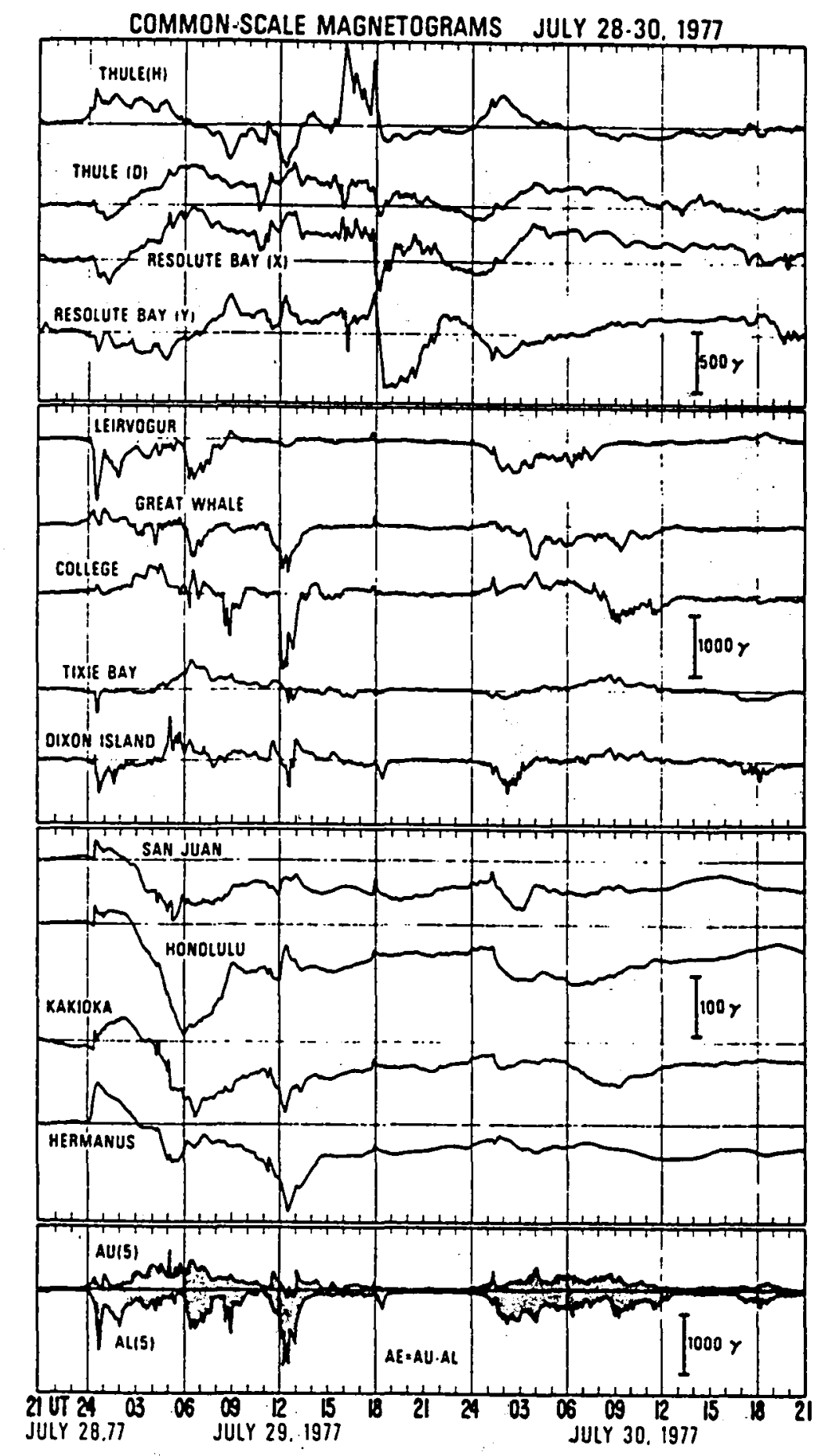

Fig. 2. Common scale magnetograms and $A E$ indices for July 28-30, 1977. 
substorm (AL > $1000 \gamma$ ) at $\backsim 1200$ UT. As previously mentioned, it is the 1200 UT suustorm upon which we concentrate in this paper.

\section{Energetic Particle Behavior at $0300 \mathrm{LT}$}

Figure 3 shows energetic electron fluxes measured by instruments on the 1977-007 spacecraft. The five energy channels shown are a representative sample of the $\sim 20$ electron channels ( $\geqslant 210 \mathrm{keV}$ ) available from 77-007 and/or ATS-6. All electron channels at $\sim 0300 \mathrm{LT}$ exhibit roushly the same sequence of events with a pronounced flux decrease, or 'dropout,' commencing at $\sim 1135$ UT [see Fennell et al., 1981]. The fluxes eventually diminish from $\sim 1$ to 3 orders of magnitude (depending on energy) but, as is especially clear in the $30 \mathrm{keV}$ channel, the measured intensities remain nonzero throughout the dropout. Hence, it is concluded that the geostationary spacecraft at 0300 LT entered a region of much reduced electron $f u x$, but they did not emerge into the extremely low intensity region of the high tail lobes. The most likely explanation is, therefore, that 77-007 and ATS entered the high-latitude plasma sheet between $\sim 1140$ and 1155. In the northern 'horn' of the plasma sheet it would be expected that energetic particle fluxes (prior to substorm onset) were lower than in the outer trapping zone, but higher than in the tail lobes.

After the flux dropout, the electron intensities appeared to recover simultaneously at all energy levels to slightly more than the predropout values. At 1200 UT there was a large increase of electron $f$ ux and this injection corresponded closely to the sharp negative bay onset seen at College (cf. figure 2). Note that lack of energy dispersion between the several energy channels suggests that the electron 'injection front' extended as far east as $0300 \mathrm{LT}$.

At 1205 UT, another substantial $\mathcal{f}$ ux increase or infection took place. This was largest and most evident in the higher ( $E \geqslant 100 \mathrm{keV}$ ) energy channels. 


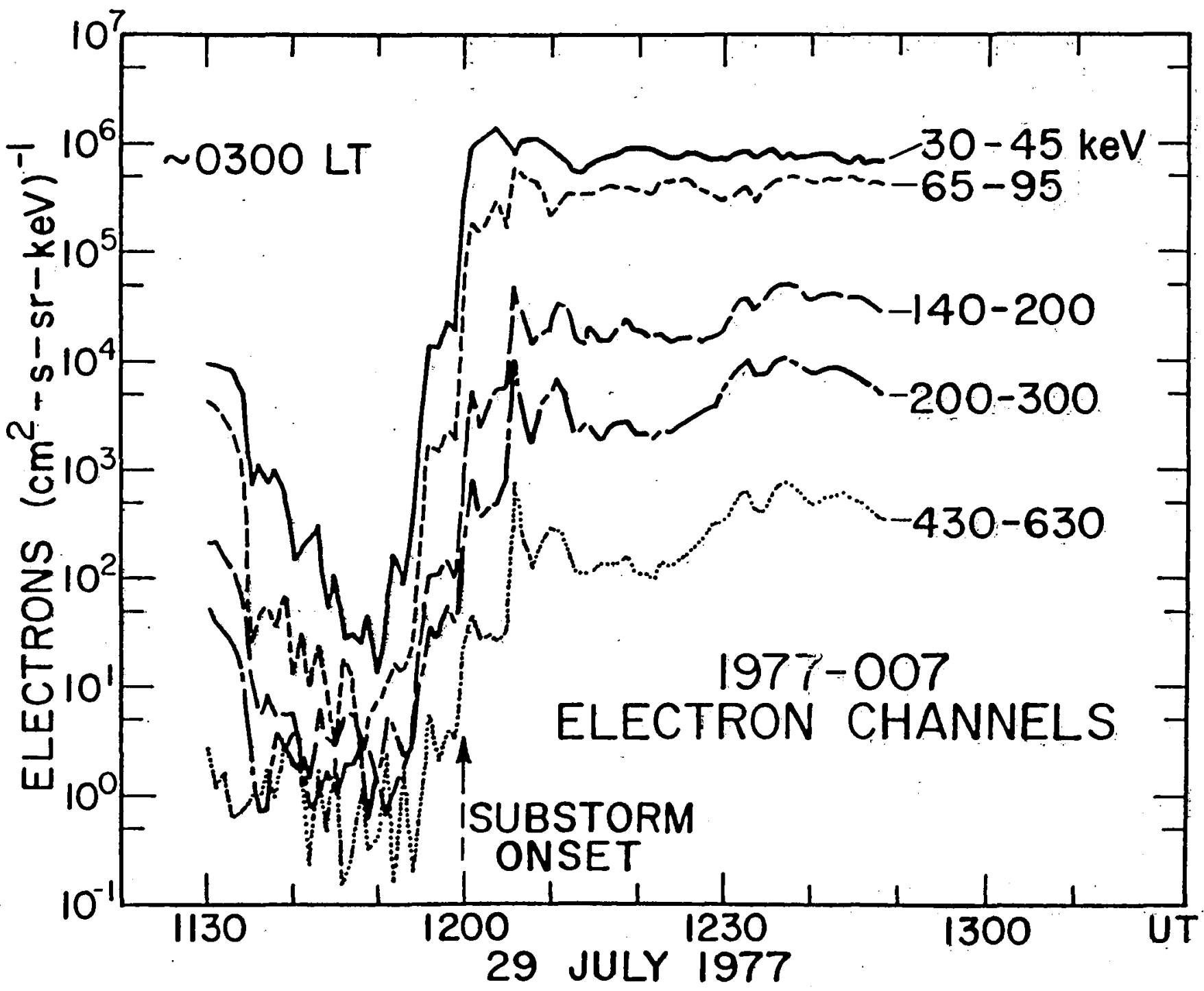

F1g. 3. Representative differential energetic electron flux profiles for the period 1130-1300 UT on 29 July 1977 at the 0300 LT spacecraft position. 
This injection spike was al so simultaneous in all energy ranges (i.e.. without energy dispersion) and this asain allows the conclusion that the injection region extended as far eastward as $0300 \mathrm{LT}$.

A third flux injection event (with some evidence of energy dispersion) occurred at $\sim 1208$ UT. Note further that after $\sim 1225$ UT the drifting high-energy electron population apparently moved azimuthally around the earth and once again passed over the spacecraft.

Given this observed electron behavior, we now turn to the energetic proton flux variations. In Figure 4, several representative low- and mid-energy proton (ion) channels from ATS-6 are shown. The 18-20 keV channel is from the $U$. of New Hampshire plasma experiment while the other four channels (33-150 keV) are from the NOAA energetic particle experiment.

Prior to $1200 \mathrm{UT}$, the energetic protons in the range 15-150 keV exhibited behavior very similar to that of the energetic electrons seen in Figure 3 . A pronounced flux dropout was seen after $\sim 1135$ UT, but at least for particle energies up to many tens of keV the $I$ ux dropout was not total. This further suggests passage of the spacecraft into a region of reduced, but nonzero, flux. This again argues that the spacecraft entered the high-latitude plasma sheet where the presubstorm particle fluxes were intermedlate between the outer trapping region and the tail lobe.

Following the dropout, (as with the electrons) a recovery characterized by several complex fux variations was seen in the protons. Note, however, that the lowest energy proton channels showed little evidence of pronounced infections of 'new' particles since the average intensity level was the same both before and after the dropout. By contrast, the higher energy proton channels (above $\backsim 50 \mathrm{keV}$ ) appeared to show a recovery to approximately predropout $\mathcal{I}$ ux values $(1155-1200$ UT) and then showed large $\mathcal{I}$ ux increases at 


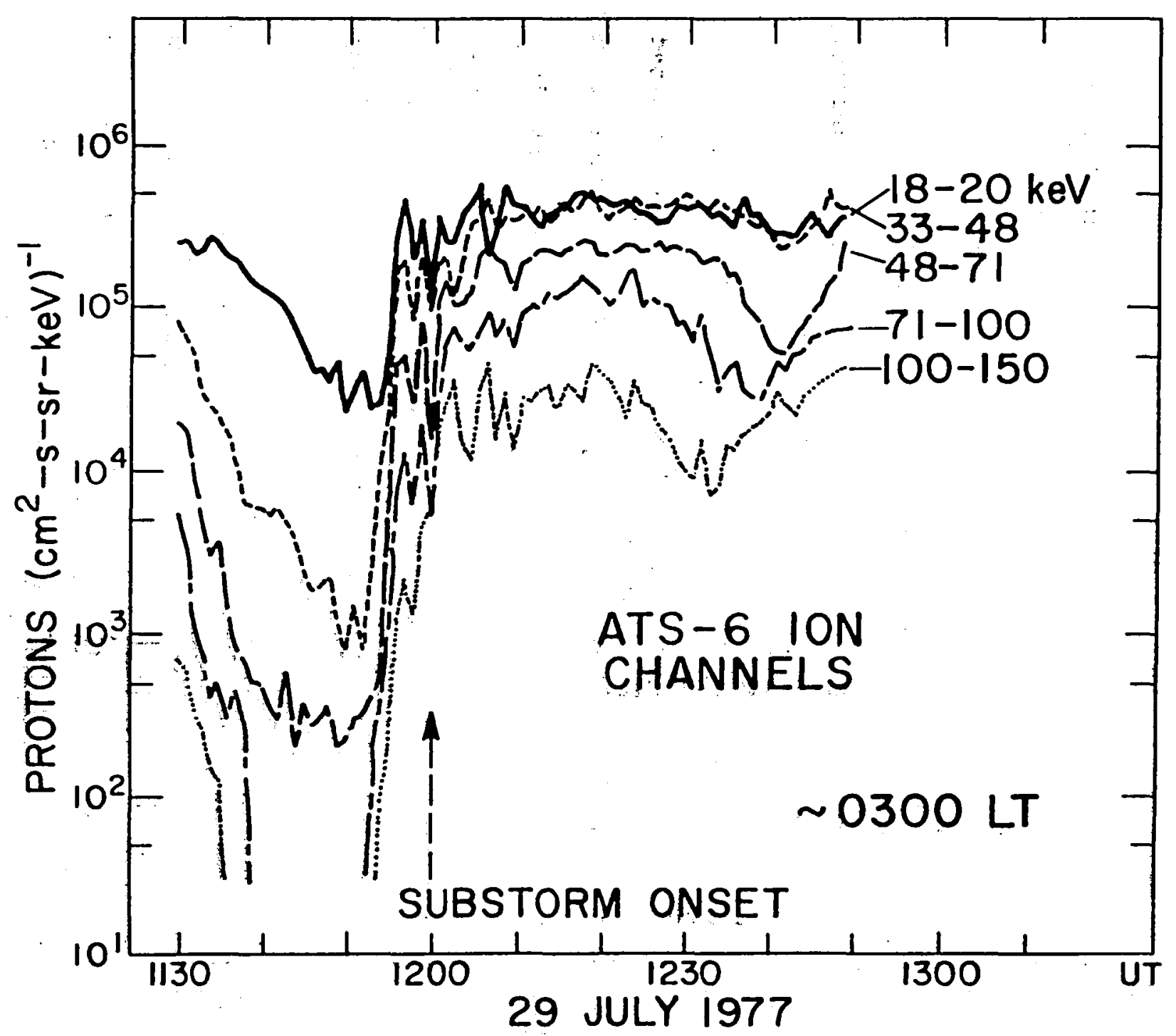

Fig. 4. Representative differential energetic proton $f$ lux profiles for the period 1130-1300 UT on $29 \mathrm{July} 1977$ at the 0300 LT spacecraft position. 
substorm onset, 1.e. at 1200 UT. This compares well with the electron injection morphology of Figure 3 .

The high energy proton data acquired concurrently at 77-007 are shown in Figure 5. The upper panel shows that 145-34n keV protons al so exhibited II ux -dropout-recovery sequence just as the electrons and low-energy protons did. The recovery fuxes (1155-1200 UT) were a factor of \& 4 higher than prior to the dropout at 1130 UT. In the lower panel of Figure 5 it is seen that the very high energy proton $(E>0.4 \mathrm{MeV}$ ) I uxes were quite low before 1135 UT ( $\mathrm{J}$ ( $1 \mathrm{~cm}^{-2}-\mathrm{s}^{-1}-\mathrm{sr}^{-1}-\mathrm{keV}^{-1}$ ) and were near background during the dropout period $(1135-1155$ UT)

In Figure 5 it is seen that the injection features described above for electrons and mid-energy protons were perhaps even more evident in the high-energy protons measured at 77-007. Thus, the injection spikes conmencing at 1200 UT and $~ 1205$ UT became progressively sharper and more distinct up to at least several hundred keV.

One of the most striking aspects of the data in the lower panel of Figure 5 is the appearance of the very regular, periodic proton drift-echo pulses [cf. Belian et al., 1978 and Baker et al., 1979]. As has been welldocumented in the literature, these high-energy proton pulses are injected Into the outer radiation zone at substorm onset and maintain their discrete identity sufficientiy long to drift azimuthally around the earth many times. In this case, it is seen in the $0.8-1.0 \mathrm{MeV}$ channel, for example, that at least four 'echo' pul ses were recorded. In a more detailed analysis section below we will return to the information provided by the drift echo data.

\section{Energetic Particle Behavior at $0700 \mathrm{LT}$}

Figure 6 is the $0700 \mathrm{LI}$ counterpart to Figure 3 , i.e.. it shows representative energetic electron channel measurements for the $1130-1300$ UT period on 


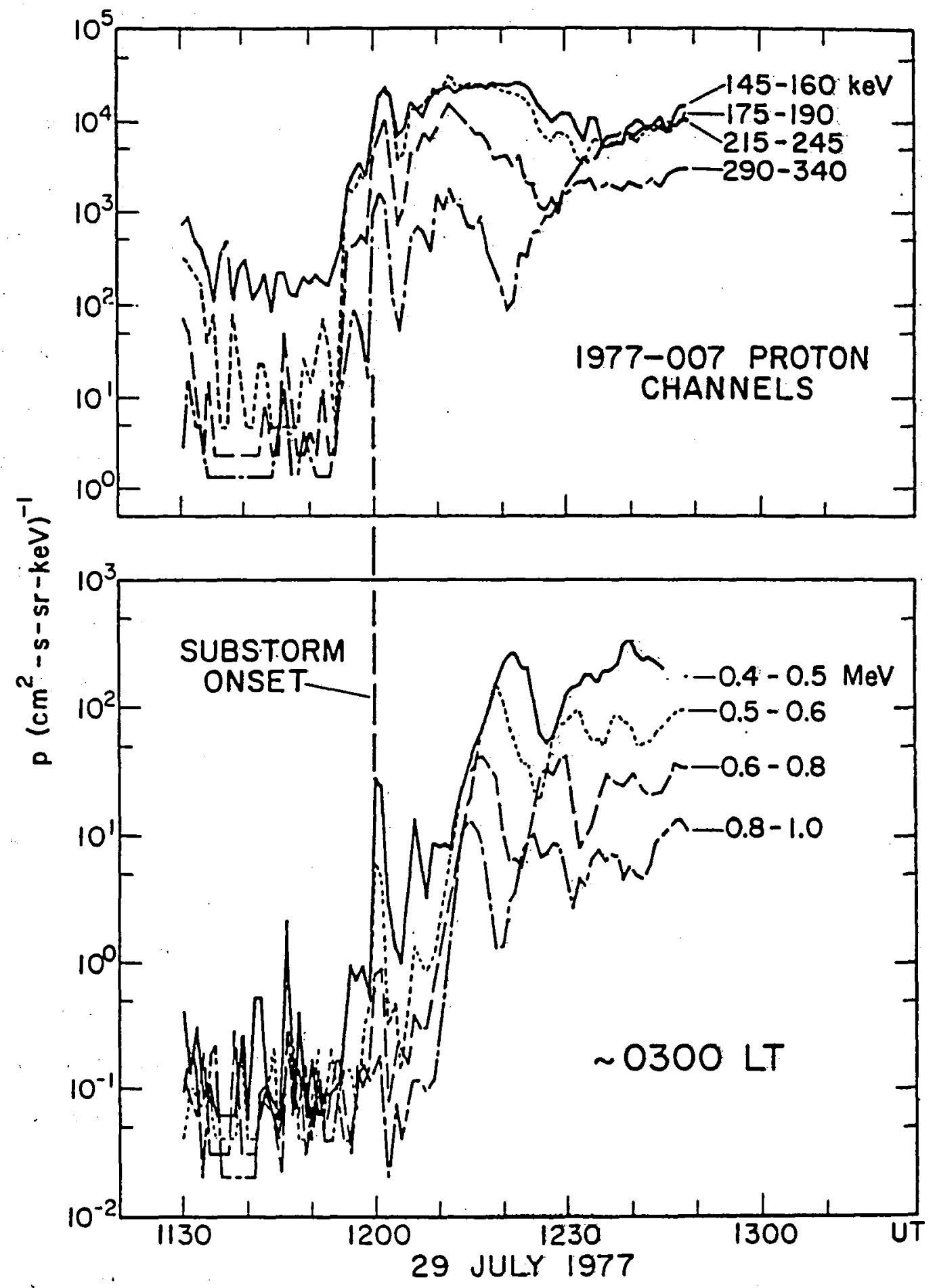

Fig. 5. High-energy proton data at the 0300 LT spacecraft position for 1130-1300 UT on 29 July 1977. 


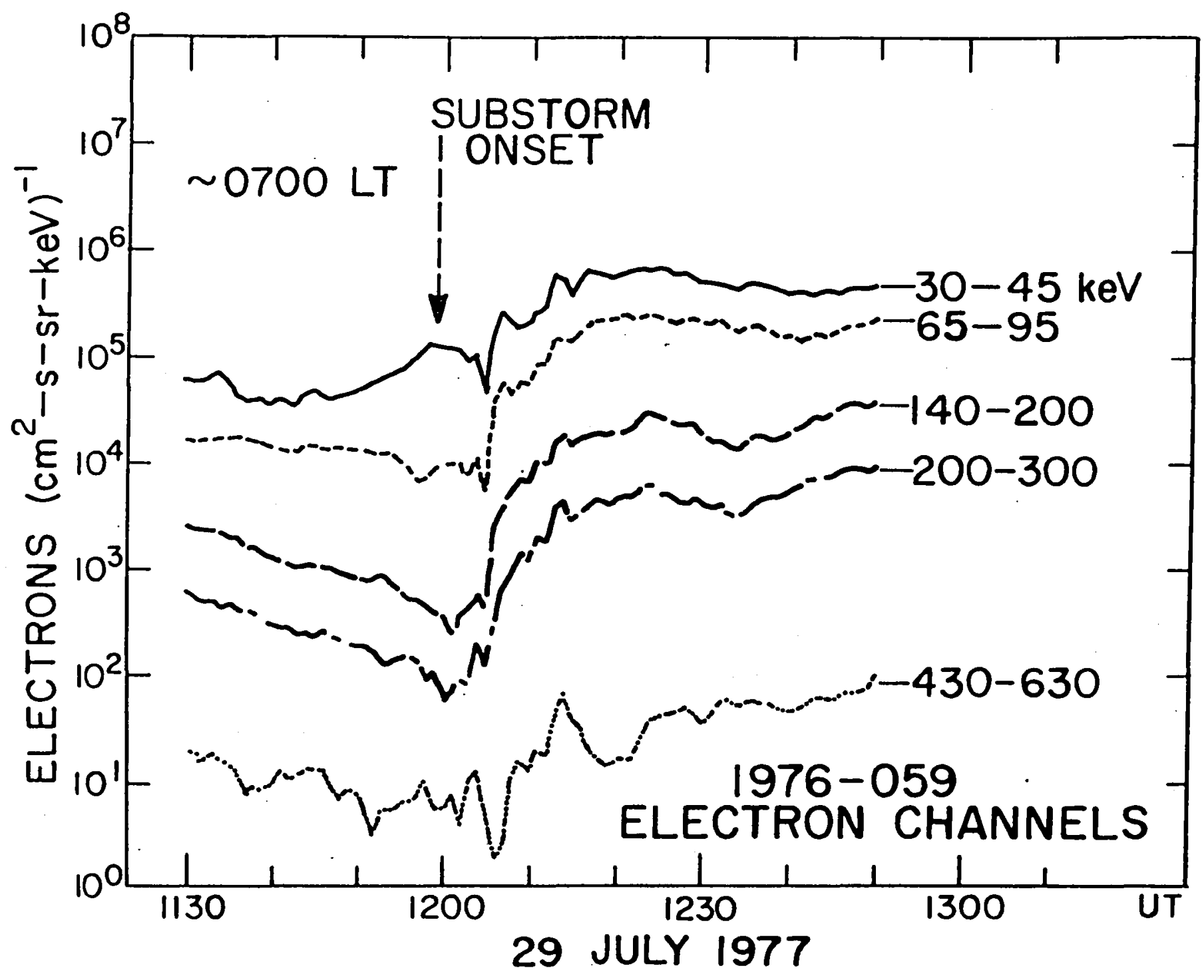

F1g. 6. Same as Figure 3 for the 0700 LT spacecraft position. 
29 July. Note that except for the lowest energy channel, there was a gradual flux decline between 1130 and $\backsim 1200$ UT. There was, however, no evidence for the major flux dropout seen in the midnight sector (as revealed by 77-0n7/ATS observations).

After $\sim 1205$ UT there were substantial flux increases in all electron energy channels. These increases were gradual in character with apparent energy dispersion effects [Arnoldy and Chan, 1969]. These observations are consistent with the electrons being injected over a broad front near local midnight (actually extending as far east as $\sim 0300$ LT) and subsequently drifting eastward to the 76-059/GOES location.

Energetic proton data from spacecraft 1976-059 (0700 LT) corresponding to those shown in Figure 5 are presented in Figure 7. In that figure, the upper panel summarizes the $145-340 \mathrm{keV}$ flux variations while the lower panel sumarizes the variations of the very energetic component ( $P>0.4 \mathrm{MeV}$ ).

As was seen in Figure 6 for the electrons, the proton fluxes shown in Figure 7 also exhibited a gradual flux decline prior to 1200 UT, but showed no major flux dropout. The behavior of the proton Iuxes at 0700 LT after $n$ 1200 UT was highly energy dependent. Up to is $250 \mathrm{keV}$, the proton fluxes appeared to recover gradualiy and indistinctly with some possible energy dispersion. By contrast, the $>0.4 \mathrm{MeV}$;proton population exhibited a very clear onset with considerable energy dispersion. As is evident from the lower panel of Figure 7, the high-energy proton behavior was of the clear drift-echo character. Careful comparison of the details of shape and timing of the pulses in Figure 7 with those of Figure 5 shows two things:

(1) The pulse shapes at 03 and 07 LT were remarkably similar in width and amplitude for any given energy channel; and

(2) An identifiable drift-echo pulse in any given channel at 07 LT appeared slightly before the same pulse appeared at 03 LT. 


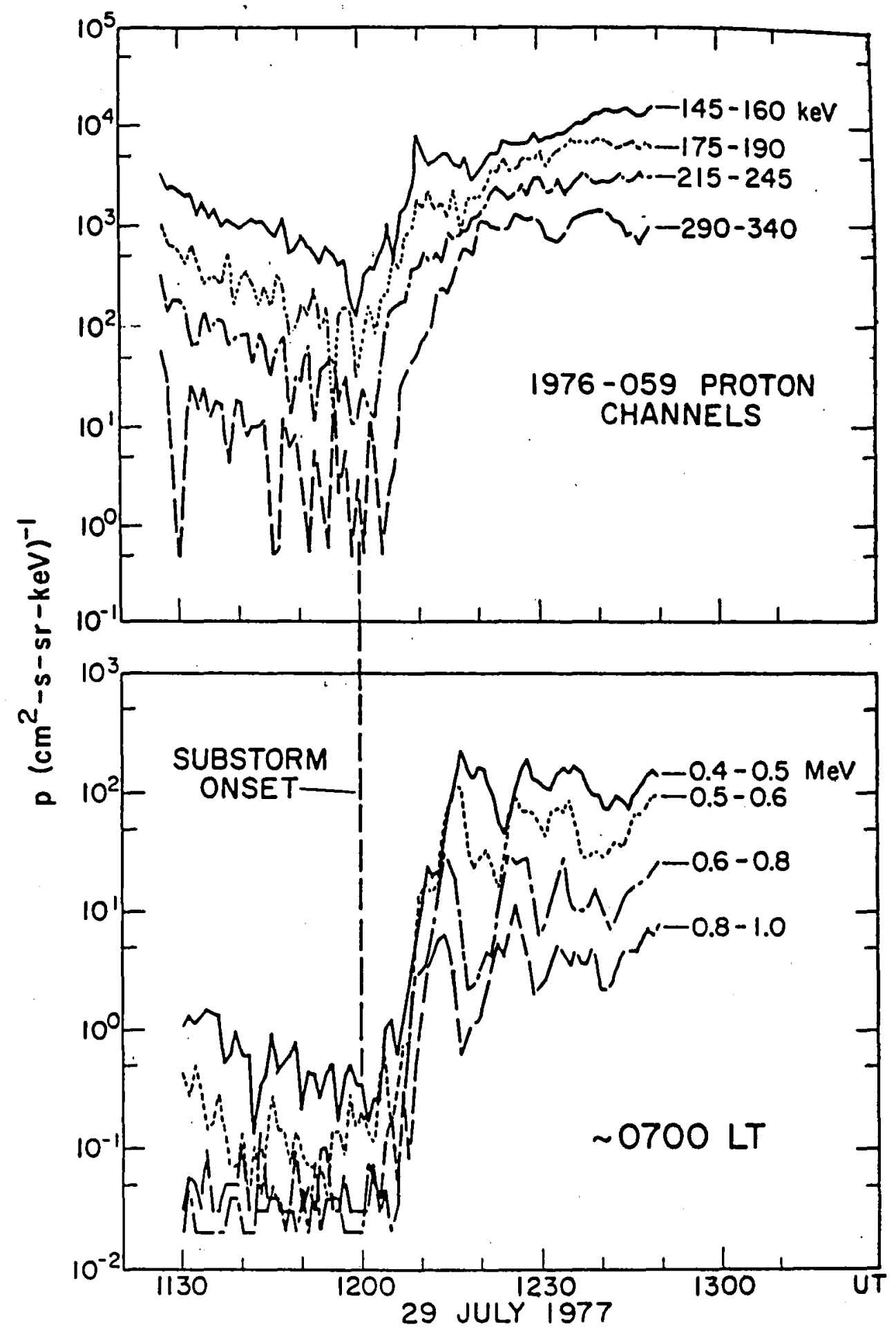

Fig. 7. Same as Figure 5 for the 0700 LT spacecraft position. 
It is concluded that essentially all of the proton results seen at the 76-059/GOES location can be accounted for by an injection of protons near midnight with a subsequent westward drift completely around the earth to the 07 LI position. The complex recovery behavior of $150-250 \mathrm{keV}$ proton $\mathrm{Iuxes}$ prior to $s$ 1225. UT appears to have been primarily adlabatic and will be discussed further below. The width of the proton injection regions around local midnight are progressively broader at lower and lower energies.

\section{Energetic Particle Behavior at 130 n LT}

Figures 8 and 9 show the electron and proton fluxes, respectively, measured at the location of GEOS-1. The data are shown in the form of stacked energy spectra in each instance. In the case of both particle species, the lowest energy channels show a gradual flux decrease between is 1130 and 1200 UT followed by a gradual recovery. Only in the higher energy channels (E \& 80 keV) was the recovery very sharp or dramatic. The $f$ ux recoveries in both particle species showed very clear energy dispersion with the recovery occurring first in the higher energy channels. This feature is consistent with substorm infection of energetic particles (broadly) near midnight with subsequent drift of the particles to the 1300 LT position.

\section{Phase Space Density Variations}

In the foregoing section, we have discussed pronounced flux increases in terms of injections. That is, we have presumed that the fux enhancenents actually corresponded to new or 'fresh' particles transported to. or accelerated in the vicinity of, geostationary orbit. In order to confirm this supposition, we have evaluated the particle distribution functions at constant first adiabatic invariant [Schulz and Lanzerotti, 1974 ]. 


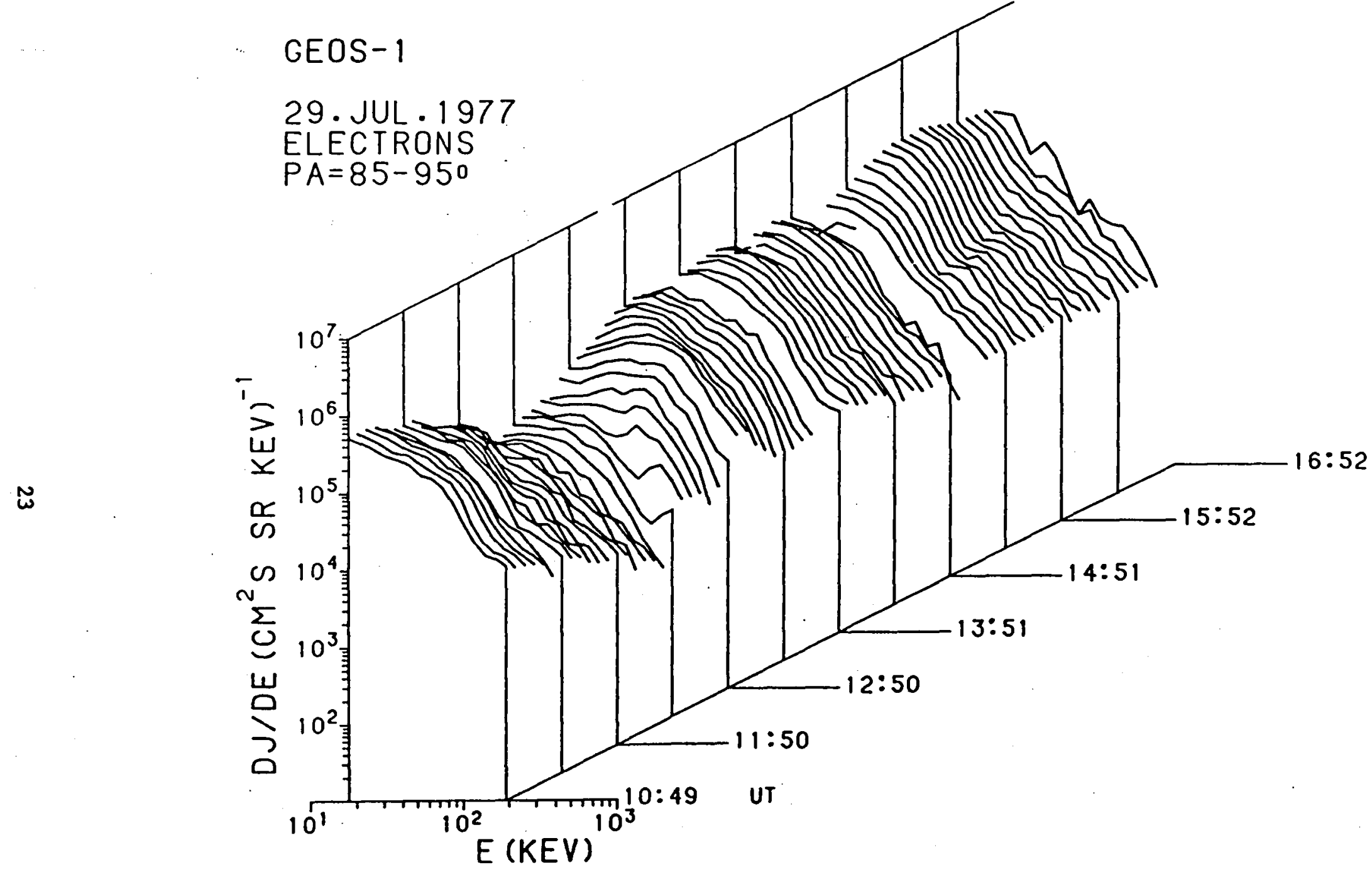

F1g. 8. GEOS-1 (1300 LT) energetic electron stacked-spectrum data for 29 July 1977. 


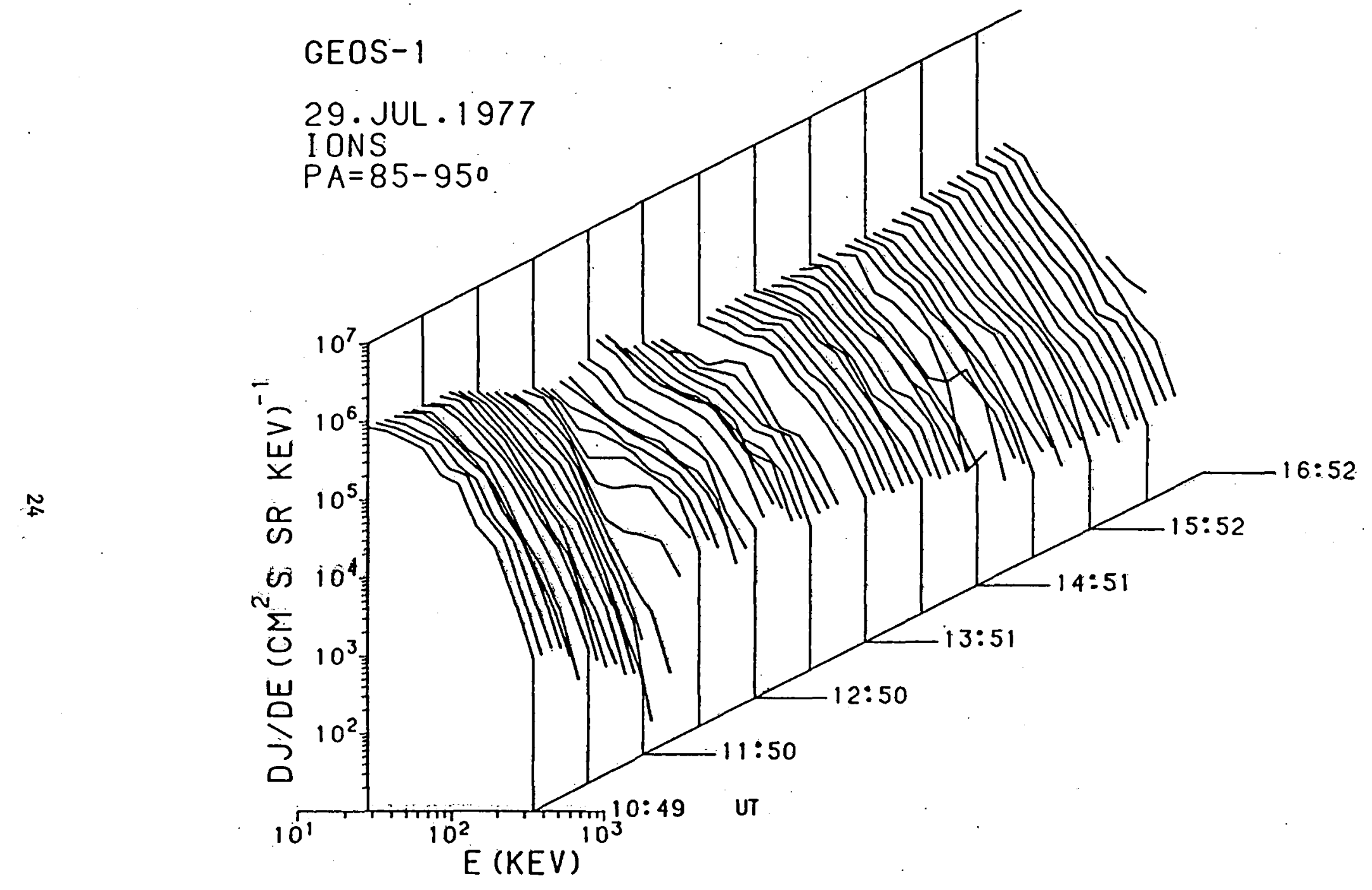

Fig. 9: GEOS-1 (1300 LT) energetic proton stacked-spectrum data for 29 July 1977. 
The phase space density, or distribution function, of a particle population can be defined in terms of adiabatic invariants and time:

$$
f(\mu, J, t)=j / p^{2}
$$

Here, $\mu$ is the first adiabatic invariant (magnetic monent), $J$ is the second Invariant, $t$ is time, $j$ is the directional differential particle flux, and $p$ is the relativistic momentum. Taking $j$ to be the equatorial perpendicular flux and $J \approx 0$, the phase space density at constant first invariant is given by

$$
f(\mu, t)=j / 2 m_{0} \mu B
$$

where $m_{0}$ is the particle rest mass and $B$ is the total equatorial magnetic field streng th.

As is evident from Eq. (2), the advantage of studying the phase density at constant $\mu$ is that adiabatic (magnetic field) variations are removed. Thus true particle density increases or decreases are revealed and sources or sinks of particles can be identified. In particular this analysis can reveal whether or not new particles were injected in the 1200 UT substorm on 29 July. Figure 10 shows exemplary spectra which were obtained at various times for this event period. The panels on the left show spectra for the $03 \mathrm{LT}$ spacecraft grouping, while the panels on the right show similar data for the 07 LT grouping. The upper panel in either case shows $f$ for electrons, while the lower panels show $f$ for protons.

As is evident from Figure 10, the data are distributed relatively accurately according to a simple exponential spectrum. This is particularly true below in $300 \mathrm{keV}$. The dashed line accompanying each set of data is the least-squares fit to the observed particle distribution where the fit is given by 


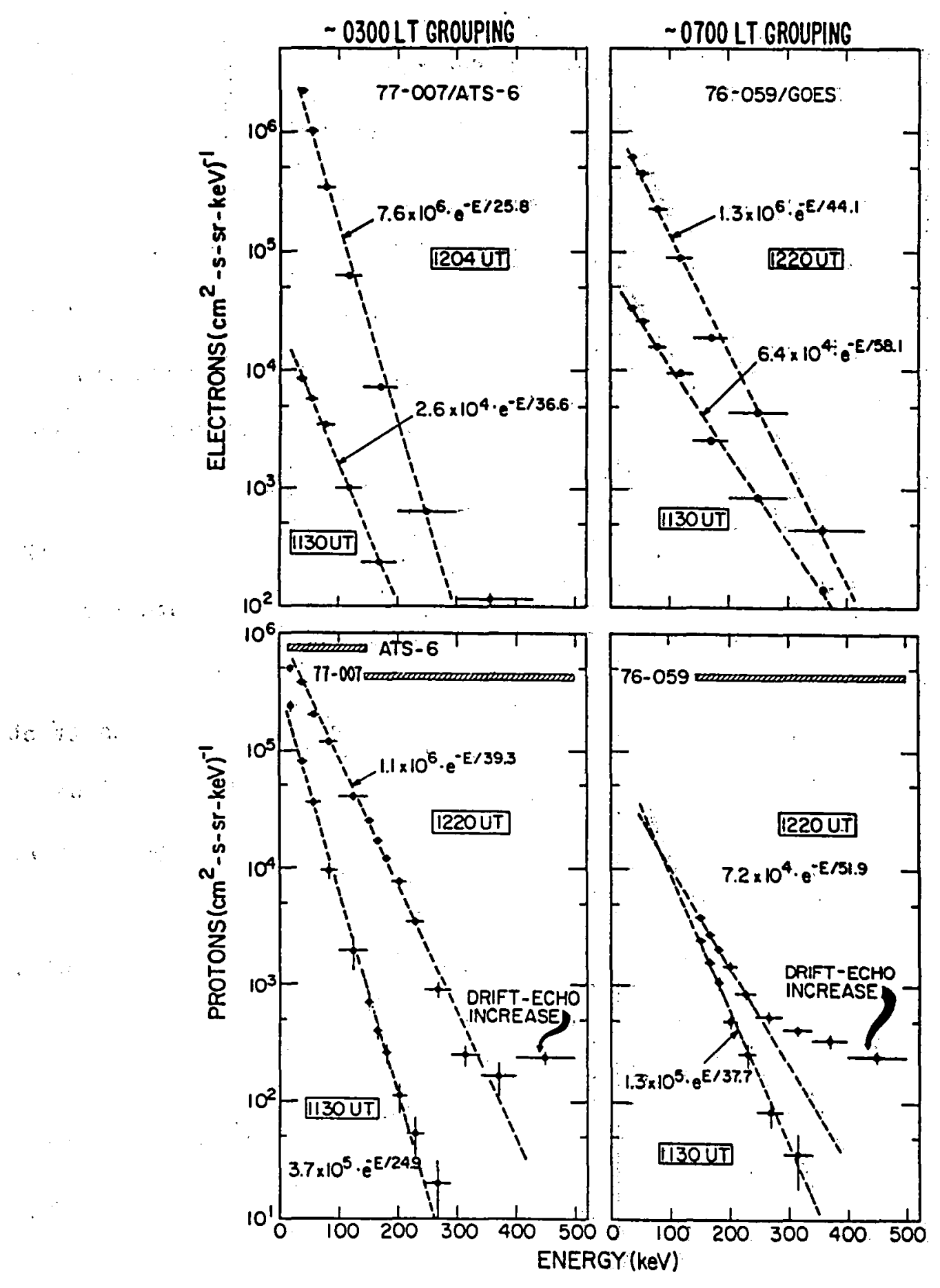

Fig. 10. Differential energy spectra for electrons (upper panels) and protons (lower panels) at the UT's indicated near each data set. Spectra taken at $\sim 0300 \mathrm{LT}$ are shown on the lefthand side while spectra taken at $\sim 0700$ LT are shown on the righthand side. Dashed lines show leastsquares fits to the data points. 


$$
J=K e^{-E / E_{0}}
$$

and has units of particles $\left(\mathrm{cm}^{2}-s-s r-k e V\right)^{-1}$. Except in the highest proton energy ranges after $\backsim 1220$ UT (where drift-echo effects are dominant), the spectral fits provide an excellent analytical representation of the observed spectra. Our procedure in the present analysis, therefore, has been to fit (for each $1-\min f l u x$ average) the observed energy spectrum to obtain $K(t)$ and $E_{0}(t)$. Given these fits, we thus have $j(E, t)$ to be used in $E q$. (2).

The other required information for phase density calculation, is the total magnetic field strength. In Figure 11 we show the values of $\mid$ 胡 for the 0300 and 0700 LT spacecraft locations. The largest variability, as might have been expected, was seen in the nighttime sector at the ATS-6 location. Because one component $(Y)$ of the ATS -6 magnetometer [McPherron et al., 1975] was inoperative at the time of these measurements, the inferred field ine direction from electron anisotropy data at 77-007 was used to complement ATS field data. In a CDAW-2 algorithm procedure the two measured ATS-6 field components ( $X$ and $Z$ ) and the field line direction from 77-007 were sufficient to provide the total field vector, $\vec{B}$, at $\sim n 30 n \mathrm{LT}$.

Combining the magnetic field data of Figure 11 with energy spectral data for each minute between $\sim 1130$ and 1300 IT $\mathrm{g}$ ave us the desired phase space densities at constant $\mu$. The ranges of $\mu-v a l u e s$ selected for investigation were chosen as follows. The minimum and maximum kinetic energies of electron and protons measured on any of the six observing spacecraft were first considered. The minimum energy measured was $E_{\min }$ " $10 \mathrm{keV}$ whereas the maximum energy channel from which useful data were obtained was $E_{\max } \sim 1.0 \mathrm{MeV}$. The 


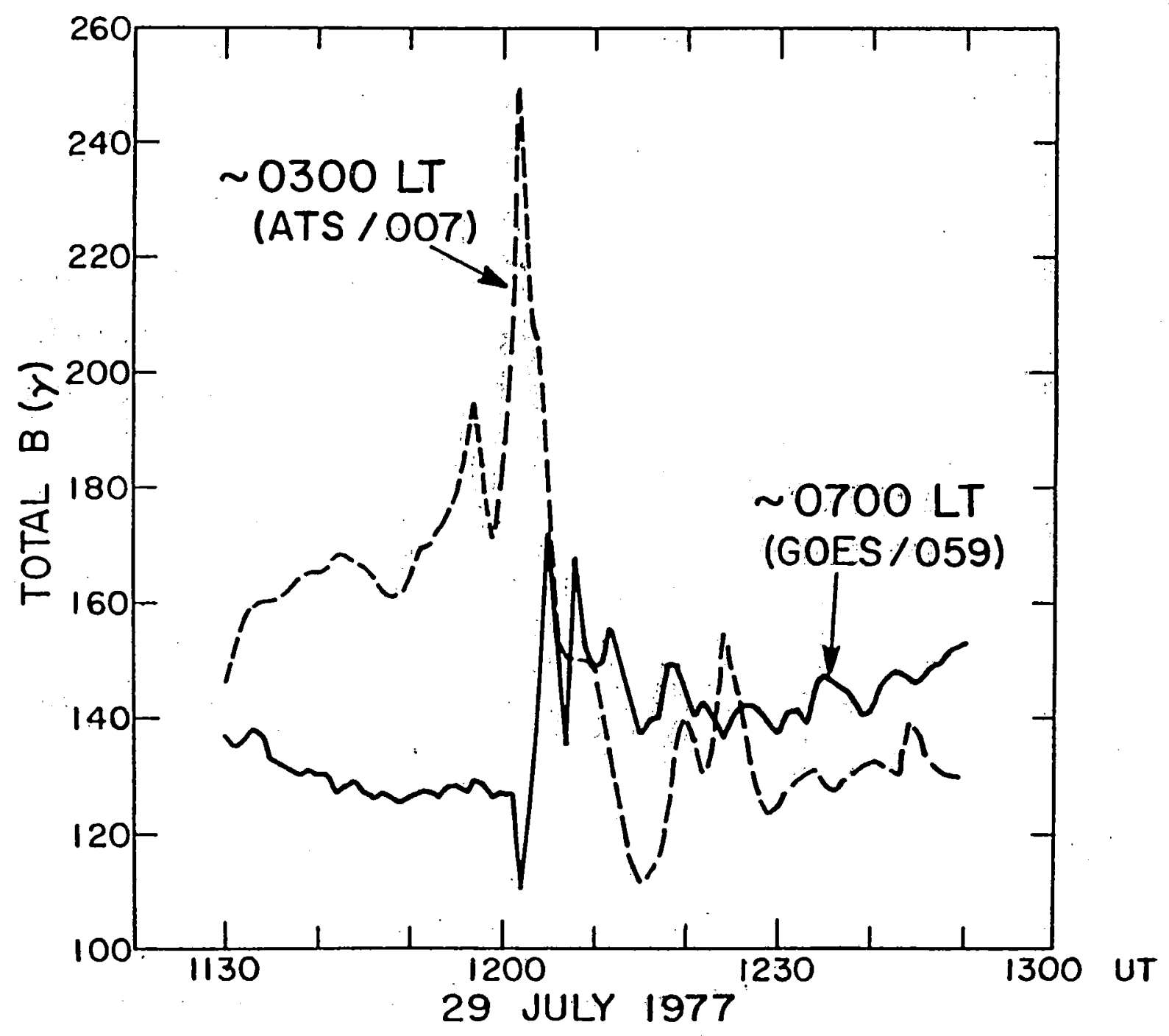

Fig. 11. Total magnetic field strength variations for the $1200 \mathrm{UT}$ substorm at the 0300 and 0700 LT grouping positions studied in this paper. 
measured range of $B$, sim1larly considered, was $B_{\min } \sim 10 n \gamma$ and $B_{\max } \sim 250 \gamma$. Thus, the $\mu$ range was

$$
\frac{E_{\min }}{B_{\max }}<\leqslant \frac{E_{\max }}{B_{\min }}
$$

and with some spectral extrapolations, a useful range of $\mu-v a l$ ues in this case was $\sim 1-1000 \mathrm{MeV} / \mathrm{g}$ auss.

Figure 12 shows examples of the phase space densities for electrons at $\mu=$ 1. 10, and $100 \mathrm{MeV} / \mathrm{G}$. The most evident features in the upper panel (77-007/ATS grouping) were the following:

(1) Even with removal of adiabatic effects, the flux dropout persists;

(2) The phase space densities at constant $\mu$ were identical before the dropout ( $\sim 1130$ UT) and after the dropout ( $\sim 1155$ UT):

(3) True phase space density increases were observed for all magnetic manents (energies) after 1200 UT.

The points above, therefore, demonstrate that in a broad sector near local midnight there was a large scale boundary motion which took the observing spacecraft into a low density region (i.e., across a spatial discontinuity). This thinning-like event clearly preceded the substorm onset. Prior to the substorm onset the midnight-sector spacecraft al so returned to a predropout density configuration for several minutes (1155-1200 UT); this, therefore, . clearly was not an injection event. At $\sim 12 n 0$ UT a clear injection of new or 'fresh' particles occurred for all magnetic moments.

The lower panel of Figure 12 shows the electron density variations at 07 LT. Comparison of these results with Figure 6 shows that at this location essentially al $\mathrm{flux}$ variations before $\backsim 1205$ UT were adiabatic. Viewing the phase space densities in this region of the magnetosphere shows essentially 


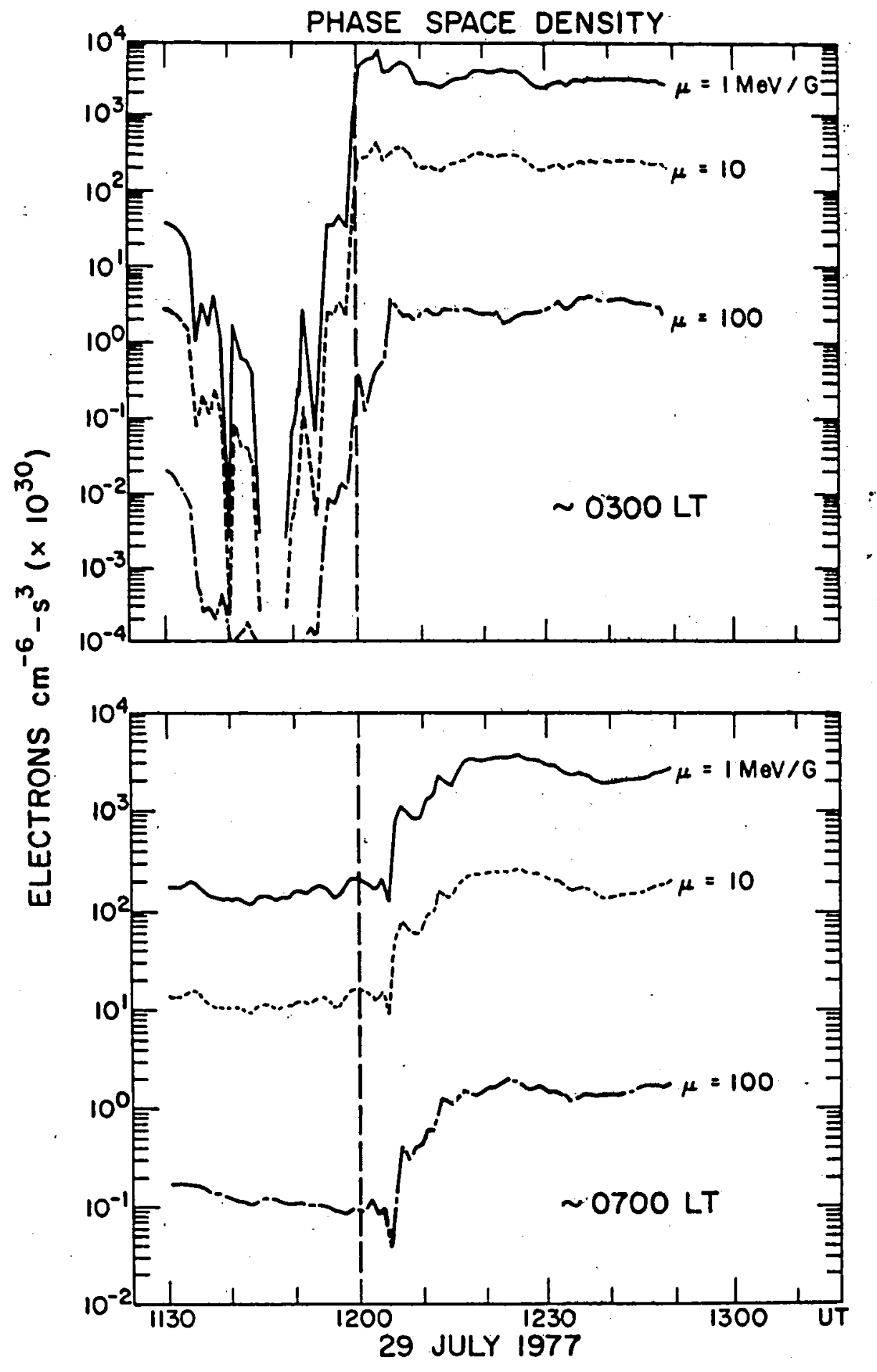

Fig. 12. Electron phase space density variations (computed as described in the text) for the 1200 UT substorm period. Densities at constant first invariant values $(\mu$, as labeled) are plotted. 
flat profiles prior to 1205, a density dip at $\backsim 1205$, and energy-dispersed density increases after $\sim 1206$ UT, consistent with injection and drift from the west.

Proton phase space density variations are shown in Figure 13 for $\mu=1$, -50, and $300 \mathrm{MeV} / \mathrm{G}$. Compared to the electron data of Figure 12, much more variability was seen in the proton density profiles. This in part represents statistical variations in the measured fuxes which translate into variations of $K(t)$ and $E_{0}(t)$ in $E q .(3)$. Nonetheless, the following features seem to be established by the data:

(1) At 03 LT, there appeared to be a phase space density increase for very low $\mu-v$ alues between $\sim 1135$ and 1150 UT while at higher $\mu-v$ al ues a clear dropout was seen;

(2) Substantial injections of new particles were seen at 0.3 LT for $\mu \geqslant 10$ $\mathrm{MeV} / \mathrm{G}$ but little clear evidence exists for injection of new protons with low $\mu-v a l$ ues;

(3) At 07 LT, there may have been some significant dips and peaks before ^ 1210 UT, particularly at high $\mu-v a l u e s$, but the most substantial effects occurred after $\sim 1210$ UT as protons azimuthally drifted westward from midnight to the 76-059/GOES location.

\section{Gradient Anisotropy Tnformation}

By examing flux and phase space density variations (particularly at the 03 LT position), it is established that new particles(up to several hundred $\mathrm{MeV} / G$ ) appeared at synchronous orbit between $\sim 1200$ and 1210 UT on $29 \mathrm{July}$. A remaining question about these particles is where the particles came from.

The best available tool for exanining the question of the general source region for the injected hot plasma and energetic particles is provided by ion gradient measurements. Because of their large gyroradii, 10-1000 keV protons 


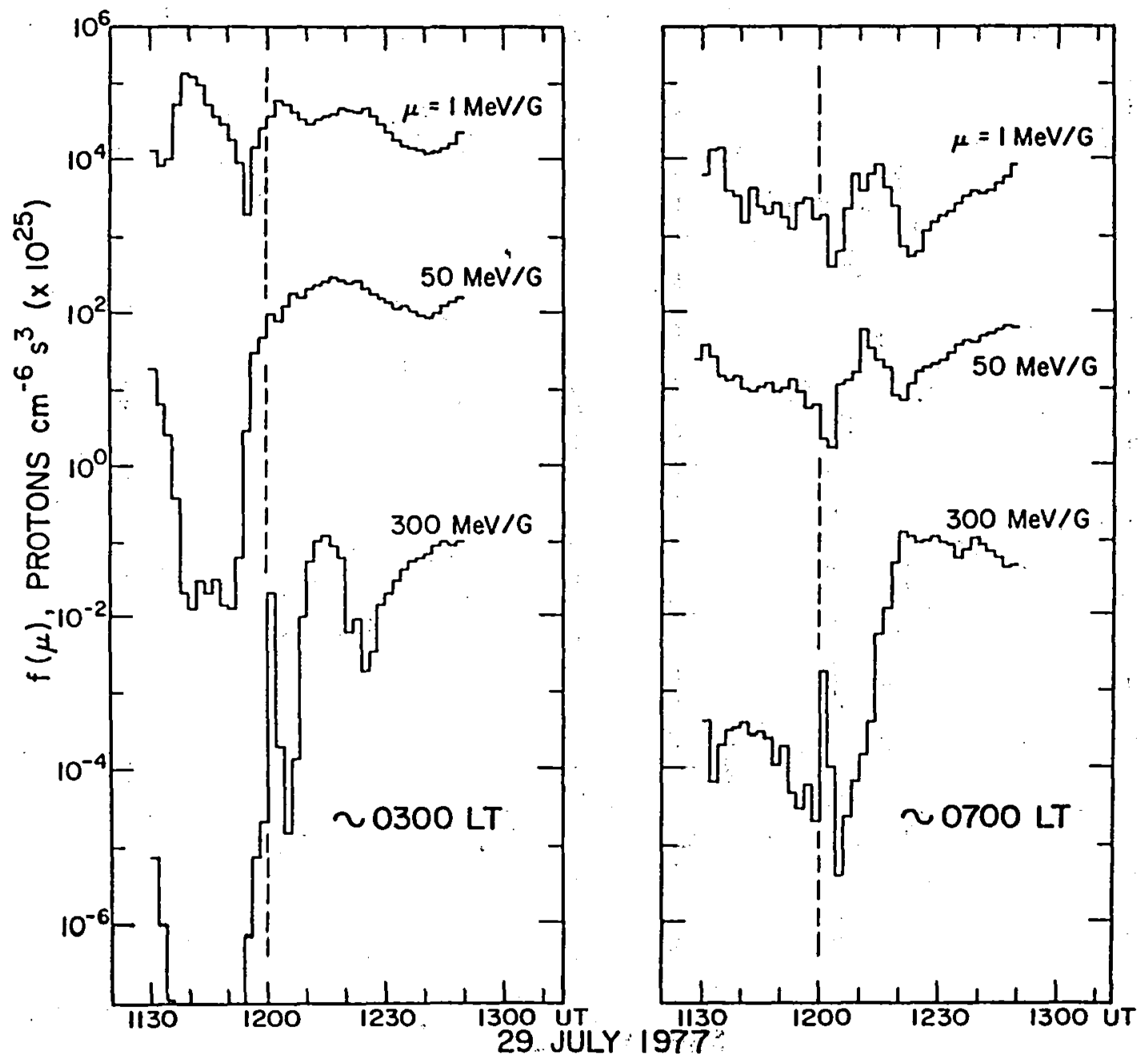

Fig. 13. Proton phase space density variations for the $1200 \mathrm{UT}$ substorm period. Densitles at constant first invariant values ( $\mu$, as labeled), are plotted. 
can provide good information about density gradients that exist within a region of strong radial intensity variations or within an injected cloud of plasma and energetic particles [Fritz and Williams, 1979; Williams et.al., 1979; Palmer et al.. 1976; Walker et al., 1976].

- The spacecraft 77-007 and 76-059 are particularly well suited for examining ion gradient anisotropies. The reason for this is that these spacecraft spin about an axis that points continually toward the center of earth and proton fluxes are measured by sensors with view directions that point radially outward perpendicular to the spin axis. Thus, a rather complete scan of ion $\mathcal{I}$ uxes is obtained on each ten-second spacecraft rotation in both the east-west sense and in the north-south sense. Given the fact that 100-200 keV protons have typical gyroradii of several hundred $\mathrm{km}\left(n 0.1 R_{E}\right)$ at synchronous orb1t, one can probe regions far removed from the spacecraft by the gradient anisotropy technique.

The gradient parameters are computed as follows:

$$
A_{E W}=(E-W) /(E+W)
$$

Where $E$ is the proton $F\left(x x\left(E_{p}>145 \mathrm{keV}\right)\right.$ measured in the sector with the detector looking eastward and $W$ is the proton $f l u x$ measured looking westward. Simil arly,

$$
A_{N S}=(N-S) /(N+S)
$$

where $N$ is the north-looking measured $\mathrm{Il} u x$ and $S$ is the south-looking measured Iux. Given the direction of the magnetic field in the vicinity of the satellites, and using the sense of gyration of protons, $A_{E W}>0$ generally implies a higher density $(f I U x)$ inside the $S / C$, whereas $A_{E W}<0$ implies a higher density outside the $S / C$. For a stretched (taillike) magnetic field orfentation (as distinguished from a completely dipolar field) one also obtains some secondary information from $A_{E W}$. Similarly, the primary information from $A_{N S}$ concerns higher $\mathrm{flux}$ above the $S / C$ ( $A_{N S}>0$ ) or below the 
$S / C\left(A_{N S}<0\right)$. The implications of various kinds of gradient anisotropies are summarized in Table 1.

We only present $A_{E W}$ and $A_{N S}$ for the 03 LI position here since this was the primary region into which the direct particle injection was observed. In order to give a sense of the magnetic field orientation at that location.

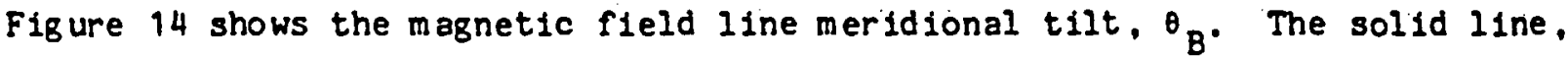
for reference, is the field tilt at $0700 \mathrm{LT}$, while the dashed line is the value of $\theta_{B}$ at 0300 LT. Note that in a dipole magnetic field, $\theta_{B}$ would be the magnetic dip angle $\left(\theta_{B}=\tan ^{-1}(2 \tan \lambda)\right)$. For the $76-059 / G O E S$ spacecraft this means the dipolar value would be $\approx 25^{\circ}$ while for 77-007/ATs the dipolar value would be $\approx 10^{\circ}$. An extreme taillike (nondipolar) magnetic configuration, with the field lines lying nearly parallel to the magnetic equatorial plane, is seen at 03 LT during the $\mathcal{I}$ ux dropout. This again seems to reinforce our Interpretation that a large-scale boundary motion took place ouring the dropout period. It al so strongly suggests that the spacecraft entered the high-latitude plasma sheet where very taillike fleld would be expected. We note that the appearance of this taillike field topology is a common precursor to substorm onset [McPherron, 1970, Baker et al., 1978] and apparently Indicates an extreme stressing of the outer masnetosphere prior to the substorm energy release at 1200 UT.

Figure 15 shows the $A_{E W}$ (upper panel) and $A_{N S}$ (lower panel) values calculated from the 77-007 energetic proton data ( $>145 \mathrm{keV}$ ). Looking at $A_{E W}$ and $A_{N S}$ together, the following sequence of events is seen. Between 1155 and $\sim 1200$, 1.e. during the recovery from the $\mathcal{I}$ ux dropout. A positive. This suggests that the higher particle density was inside the spacecraft. ANS during this same period was, for the most part, strongly negative, suggesting a high particle $\mathrm{fux}$ below the spacecraft. Since Figure 14 showed the fleld to be very taillike during this period, our contention of 
Table 1. Proton Gradient Anisotropy Information

\begin{tabular}{ccc}
$\begin{array}{c}\text { Parameter Value } \\
\text { (Primary Information) }\end{array}$ & $\begin{array}{c}\text { High Density Location } \\
\text { (Secondary Information) }\end{array}$ \\
\hline$A_{E W}>0$ & Inside $\mathrm{S} / \mathrm{C}$ & (Below-East) \\
$A_{E W}<0$ & Outside $\mathrm{S} / \mathrm{C}$ & (Above-West) \\
${ }_{\mathrm{ASS}}>0$ & Above S/C & (Inside-East) \\
$A_{\mathrm{NS}}<0$ & Below S/C & (Outside-West)
\end{tabular}




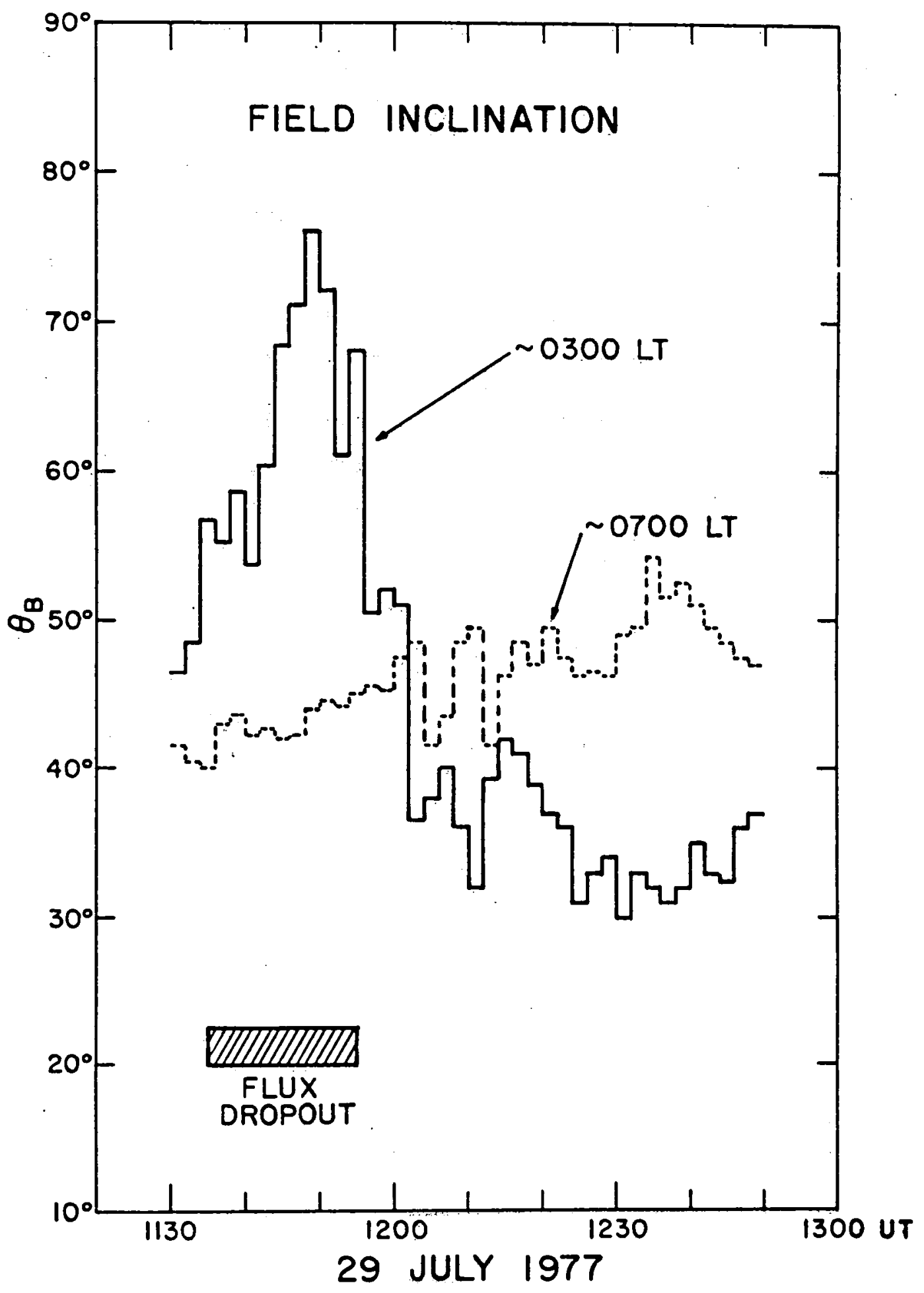

Fig. 14. Field line dipolar t1lt angle, $\theta_{B}$, inferred (as described in text) from the energetic electron anisotropy symmetry axis. A very talllike field $\left(\theta_{B}>60^{\circ}\right)$ is observed at $\sim 0300 \mathrm{LT}$. 


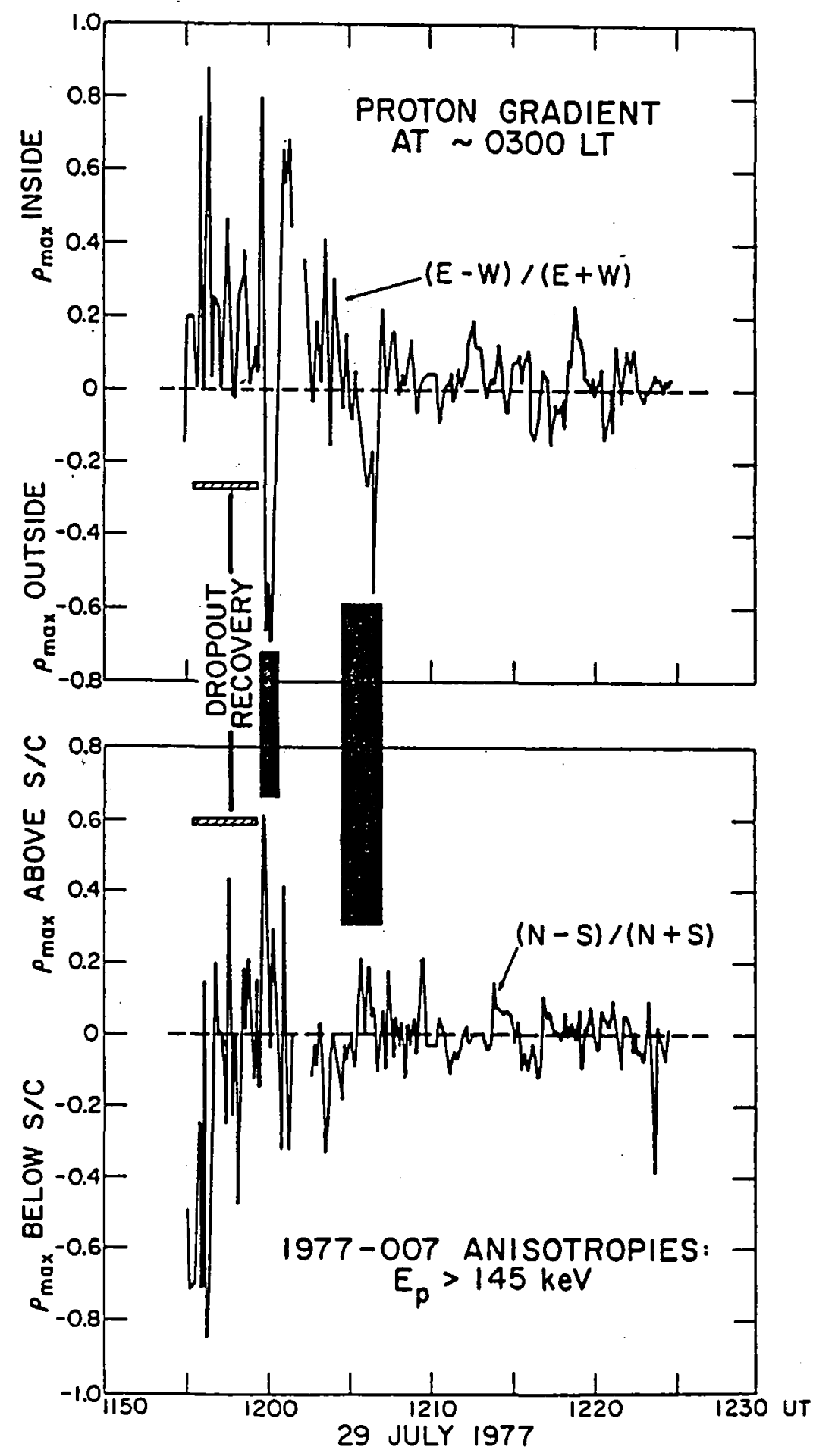

Fig. 15. Proton ( $E_{1}>145 \mathrm{keV}$ ) gradient anisotropy data for the period 1155-1225 UT at the 0300 LT position. The eastwest anisotropy is shown in the upper panel, while the concurrently measured north-south anisotropy is shown in the lower panel. 
a boundary motion during the dropout with the high flux region moving earthward and equatorward, is fully borne out. As the fluxes recover, the spacecraft were enveloped from inside and from below.

At $1200 \mathrm{UT}, \mathrm{A}_{\mathrm{EW}}$ went strongly negative. This period corresponded precisely to the first energetic particle and hot plasma injection into synchronous orbit. The character of $A_{E W}$ showed that the injected particles came from outside the spacecraft location. For this same period $A_{N S}$ was strongly positive, showing that the particles also generally arrived from above the S/C. The conclusion is therefore unambiguous in this case, viz. the injected particles arrive at $6.6 \mathrm{R}_{E}$ from the outside and from above. This very $11 k e l y$ means that these particles filled the high-latitude plasma sheet and that these filled field lines then collapsed inward over the spacecraft. After the leading edge of the particle injection passed over the spacecraft, $A_{E W}$ went strongly positive and $A_{N S}$ was weakly negative (1202-1205 UT). This indicates that the highest particle density, after the injection, Ii : generally inside $6.6 \mathrm{R}_{\mathrm{E}}$.

A second particle injection occurred (cf. Figures 3 and 5 ) at $\backsim 1205$ UT. Figure 15 shows again that these particles came from outside $6.6 R_{E}$ since $A_{E W}$ was strongly negative. Note in Figure 14 that B was more nearly dipolar by 1205 UT. Therefore, in this case $A_{N S}$ became only weakly positive during the injection. It is concluded with considerable certainty that the 1205 UT injection of energetic particles and hot plasma, as was also true for the 1200 UT case, came from outside of synchronous orbit.

The apparent 1208 UT injection of particles (see Figures 3 and 5) seemed to show energy dispersion effects, consistent with the interpretation that the injection front did not directly extend as far eastward as 0300 LT. Indeed, a substantial gradient anisotropy signature of this injection is not seen in Figure 15. 
A composite plot of the $>145 \mathrm{keV}$ proton $\mathrm{flux}$ and the computed value of ${ }_{\mathrm{EW}}$ is shown in Figure 16. The recovery sequence between 1155 and 1200 UT, the $\mathbb{I}$ ux injection at 1200 UT, and the $\mathbb{I}$ ux injection beginning at 1205 UT are all particularly evident in that rigure. Minor (but statistically significant) changes in $A_{E W}$ between 1212 and 1225 UT are also evident as subsequent small pulses of protons drift past the spacecraft, approaching from the east $\left(A_{E W}>0\right)$ and receding to the west $\left(A_{E W}<0\right)$.

\section{Drift-Echo Timing Information}

Proton drift-echo events such as shown above in Figures 5 and 7 can be used to infer times and locations of the 'centroids' of particle injections [Belian et al., 1978]. As illustrated by the detailed 10-s $\mathrm{flux}$ averages in Figure 17, the pulses of drifting protons show evidence of basically a triple structure in each pulse. These more detalled (10-s) $\mathrm{n}$ ux values have been used to carefully determine the time of the 'peak 1', 'peak 2' and 'peak 3 ' relative flux maxima for the $0.4-0.5,0.5-0.6,0.6-0.8$, and $0.8-1.0 \mathrm{MeV}$ channels at the 0700 and 0300 LT positions. The local time of the observed peak pulses (modulo $360^{\circ}$ ) was then considered versus the universal time of each peak pulse. Two drift-echo pulses could be clearly discerned in each of the two lower energy ranges, while three pulse echoes were seen at the two higher energies.

Table 2 summarizes the LI and UT data points inferred from the highresolution drift-echo data. It should be noted that discerning the individual relative 'peaks' was uncertain when the pulses overlap. On the other hand, some of the peak times, as might even be evident from the $1-m i n$ averages of Figures 5 and 7 , are quite distinct and obvious. Other of the peak times had to be judged from relatively subtle inflections in the flux profiles. Overall, the data points in Table 2 have associated UT uncertainties of approximatel $\mathrm{y} \pm 1 \mathrm{~m}$ in 


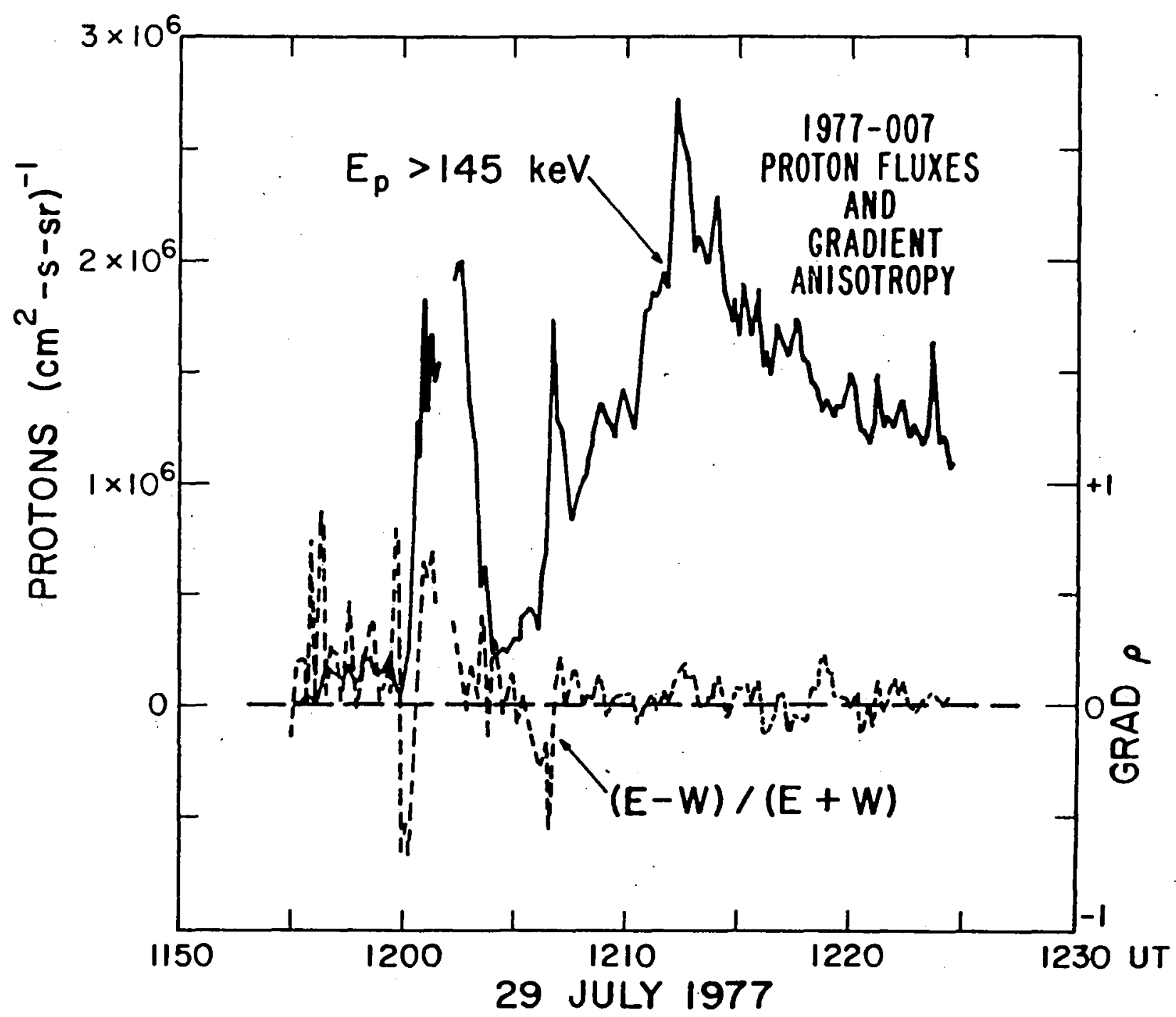

Fig. 16. A comparison of the $>145 \mathrm{keV}$ proton flux (solid line) and the associated east-west gradient anisotropy (dotted line). Strong gradient anisotropies occur as new energetic particles are injected near synchronous orbit (see text). 


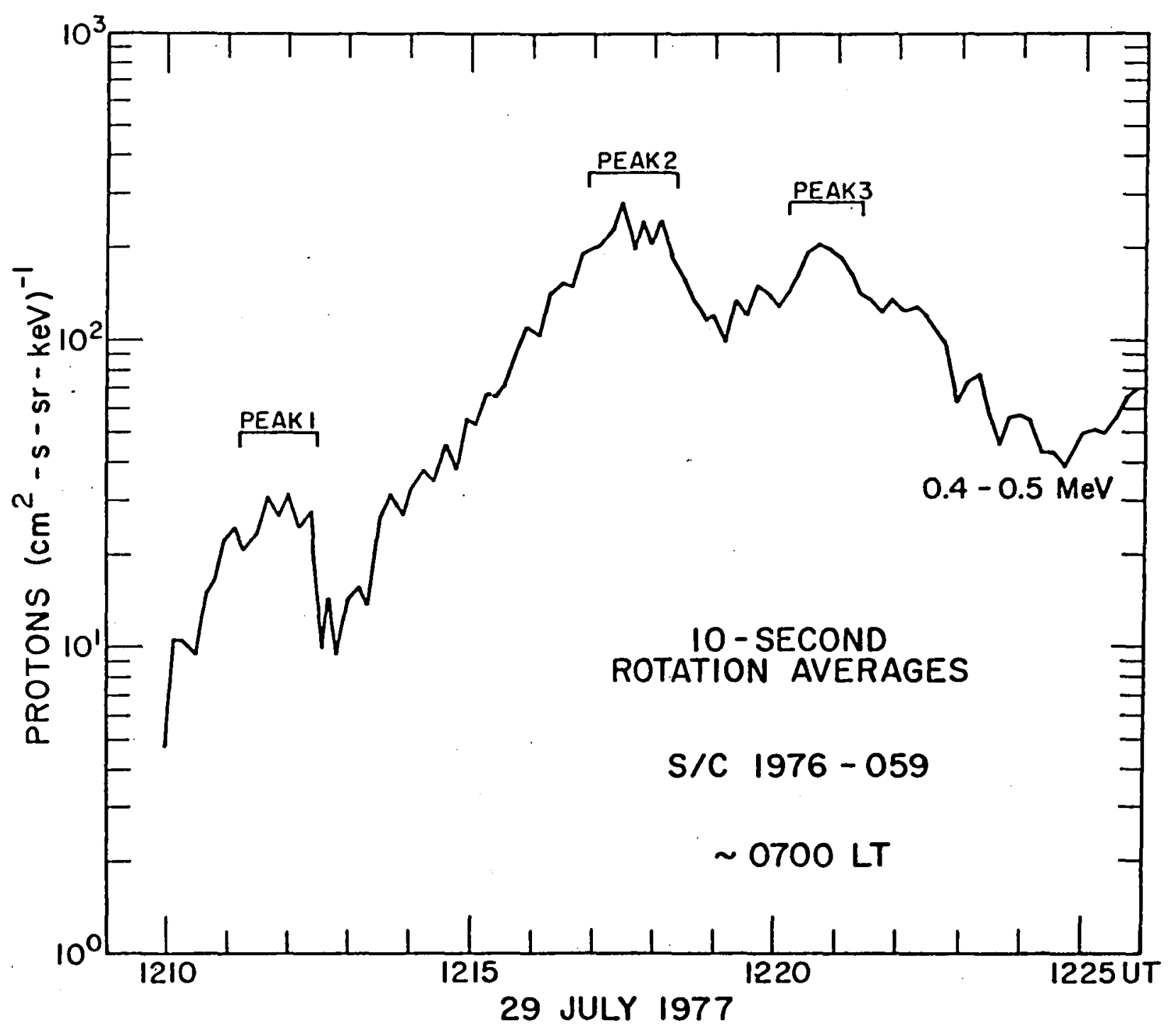

Fig. 17. High time resolution plot for the $0.4-0.5 \mathrm{MeV}$ proton channel on 1976-059 at $\sim 0700 \mathrm{LT}$. The triple peak time structure of the pulse is demonstrated. 
Table 2. Proton Drift-Echo Pulse Time

\begin{tabular}{|c|c|c|c|c|c|c|c|}
\hline Peak & $\begin{array}{c}\text { Energy } \\
(\mathrm{MeV})\end{array}$ & $s / c$ & $76-059$ & & $s / C$ & $77-007$ ( & T) \\
\hline \multirow[t]{4}{*}{$\$ 1$} & $0.4-0.5$ & 1212.0 & 1228.0 & - & 1215.0 & 1231.0 & - \\
\hline & $0.5-0.6$ & 1211.0 & 1226.0 & - & 1214.0 & 1228.0 & - \\
\hline & $0.6-0.8$ & 1209.5 & 1221.5 & 1233.5 & 1211.5 & 1222.5 & 1236.0 \\
\hline & $0.8-1.0$ & 1209.0 & 1219.5 & 1232.0 & 1210.4 & 1221.5 & 1233.5 \\
\hline \multirow[t]{4}{*}{12} & $0.4-0.5$ & 1217.2 & 1233.5 & - & 1220.5 & 1236.5 & - \\
\hline & $0.4-0.6$ & 1216.3 & 1231.0 & - & 1219.0 & 1233.0 & -- \\
\hline & $0.6-0.8$ & 1214.5 & 1225.5 & 1237.0 & 1216.0 & 1227.0 & 1238.5 \\
\hline & $0.8-1.0$ & 1213.0 & 1223.0 & $1235.0^{*}$ & 1214.5 & 1224.5 & 1235.0 \\
\hline \multirow[t]{4}{*}{$\$ 3$} & $0.4-0.5$ & 1220.5 & 12.37 .1 & -- & 1223.5 & 1239.5 & - \\
\hline & $0.5-0.6$ & 1219.5 & 1235.0 & - & 1222.5 & 1237.0 & -- \\
\hline & $0.6-0.8$ & 1217.0 & 1228.5 & 1239.5 & 1218.5 & 1229.9 & 1241.0 \\
\hline & $0.8-1.0$ & 1216.0 & 1225.5 & 1236.0 & 1217.6 & 1227.0 & 1237.0 \\
\hline
\end{tabular}

"Point not used in least-squares fit. 
Results for the several selected 76-059 and 77-007 energy channels are plotted in Figure 18. In each panel we separately plot data for each of the peak 1 through peak 3 pulses. The parameter $\phi$ is equivalent to LT (in degrees) except that it runs clockwlse from midnight (in the same sense as proton drifts) rather than counterclockwlse. For each energy channel a least-squares fit through the data points is shown.

As seen by Figure 18, it is possible to arrive at an internally consistent interpretation of all of the high-energy proton data, at both $0700 \mathrm{LI}$ and 0300 LT. This interpretation is that there were three high-energy proton injections centered in the post-midnight region and these injections each exhibited several echoes that were individually seen at both the 0700 and 0300 local times. The universal times of the injections inferred from Figure 18 are: peak 1 events, $\sim 1200 \mathrm{UT}$; peak 2 events, $\sim 1205$ UT; and peak 3 events, $\sim$ 1208 UT.

\section{Adiabatic Modeling Results}

A major underlying theme of our analysis has been that substorm energetic particles are injected in the nightside magnetosphere and that these particles subsequently are trapped and drift to positions removed from the infection site. Much of the foregoing analysis has been carried out within this framework and, generally, supports such an interpretation. However, in order to model the injection and drift more quantitatively the time-dependent convection model of Smith et al. [1979] was used.

This model follows the motions of charged particles under the influence of the gecmagnetic and electric flelds. A Volland-Stern type of convection electric field $\left(E=-\nabla \phi\right.$ and $\Phi=A R^{2}$ sin $\left.\phi\right)$ and a dipole magnetic fleld are assumed. Here $\$$ is the electric potential, $\$$ is a local time parameter measured from local midnight, and $R$ is geocentric radial distance. As shown 

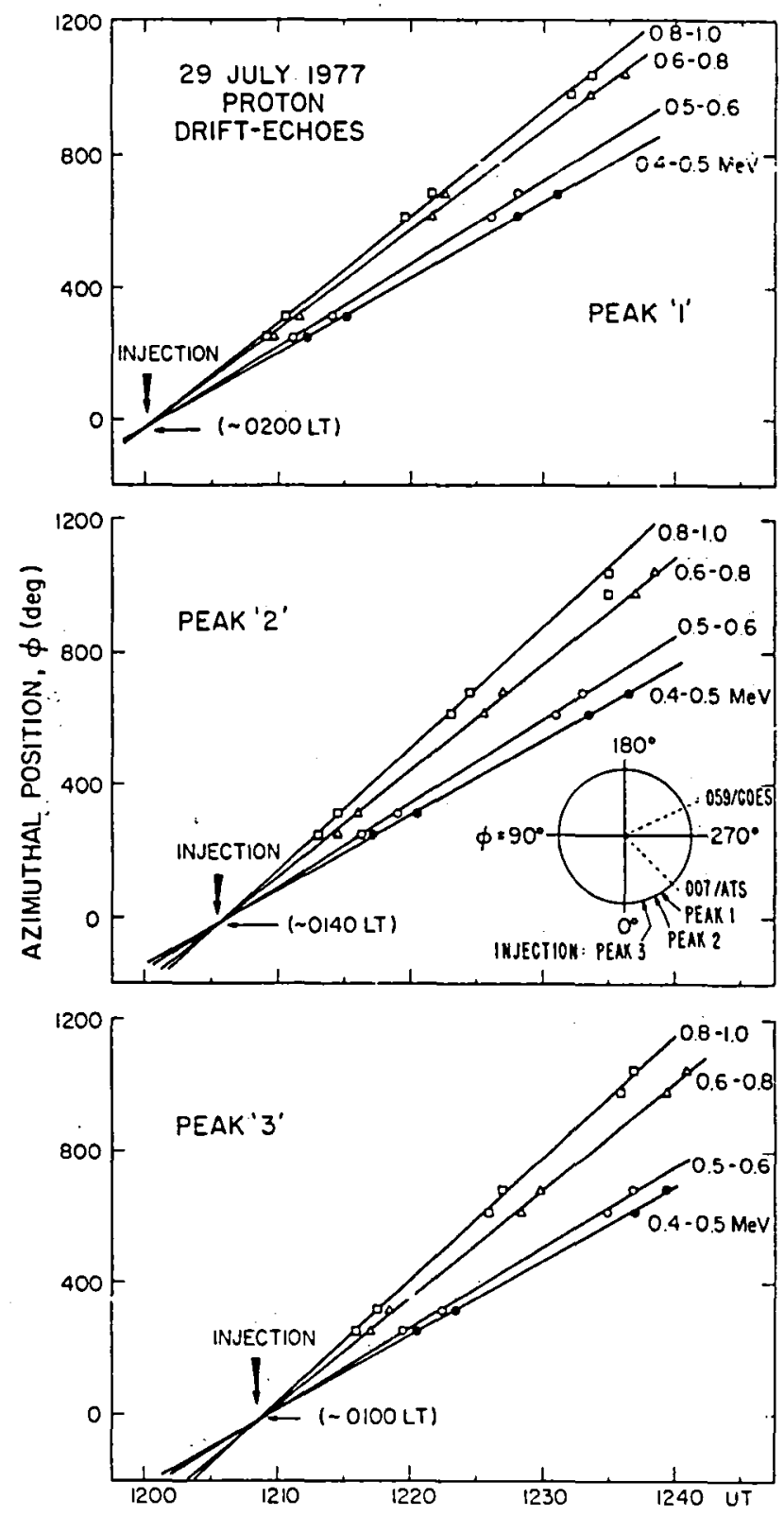

Fig. 18. Local time (' $\left.\phi^{\prime}\right)$ versus UT plots for high-energy driftecho pulses seen at S/C 1977-007 and 1976-059. As discussed in the text, the intersections of the manifolds of lines in each panel give an idea of the local time and universai time of the proton injection. The small inset polar plot in the central panel illustrates the $\mathrm{S} / \mathrm{C}$ locations and the centroids of proton injection. 
by Snith et al. [1979], the time-variation in the electric field may be characterized by the geamanetic index $\mathrm{Kp}$ which is then introduced $\mathrm{via}$ the parameter A.

Al though this large-scale convection model has been quite successful in predicting the behavior of low-energy charged particles during storms [c.f. Smith et al.; 1979], a goal of the CDAW-2 effort was to test the model for nigher energy particle injections. Figure 19 illustrates several of the results for "high-energy" trajectory simulations. In each case, protons : with $\mu=1.0 \mathrm{keV} / \mathrm{\gamma}(100 \mathrm{MeV} / \mathrm{G})$ and pitch angle $=90^{\circ}$ were injected at a boundary of $10 R_{E}$. For $\mu=100 \mathrm{MeV} / \mathrm{G}$, the kinetic energy of the protons at $L=6.6$ would be about $100 \mathrm{keV}$. In Figure 19 one-hour increments of the trajectories between 1200 and 1600 UT on 29 December are displayed. In each Instance the GEOS-1 orbit is shown for reference.

Case A shows the nominal model calculations for assumed proton injections at $2300 \mathrm{LT}$ through $0300 \mathrm{LT}$. As is evident from the figure, the normal convection model described in the preceding paragraph gives rise to untrapped particle drift trajectories which typically encounter the dayside boundary near local noon. In Figure 19B, the Volland-stern convection field was decreased to one-fourth strength in the radial range 6-10R and $1000-1400$ LT. This change causes the particles to be "pulled" back on the dayside and the relatively high-energy protons injected at 0200-0300LT are thereby trapped. (Note, however, that the boundary between the decreased field and the normal model field in case $B$ is non-physical).

Magnetic field observations in the outer magnetosphere during the substorm period under investigation indicated a gradient $(\Delta B / B)$ value much less than the normal, nonstorm value. In case $C$ of Figure 19, $\triangle B / B$ was reduced to one-half its normal value to be more consistent with observations. This 

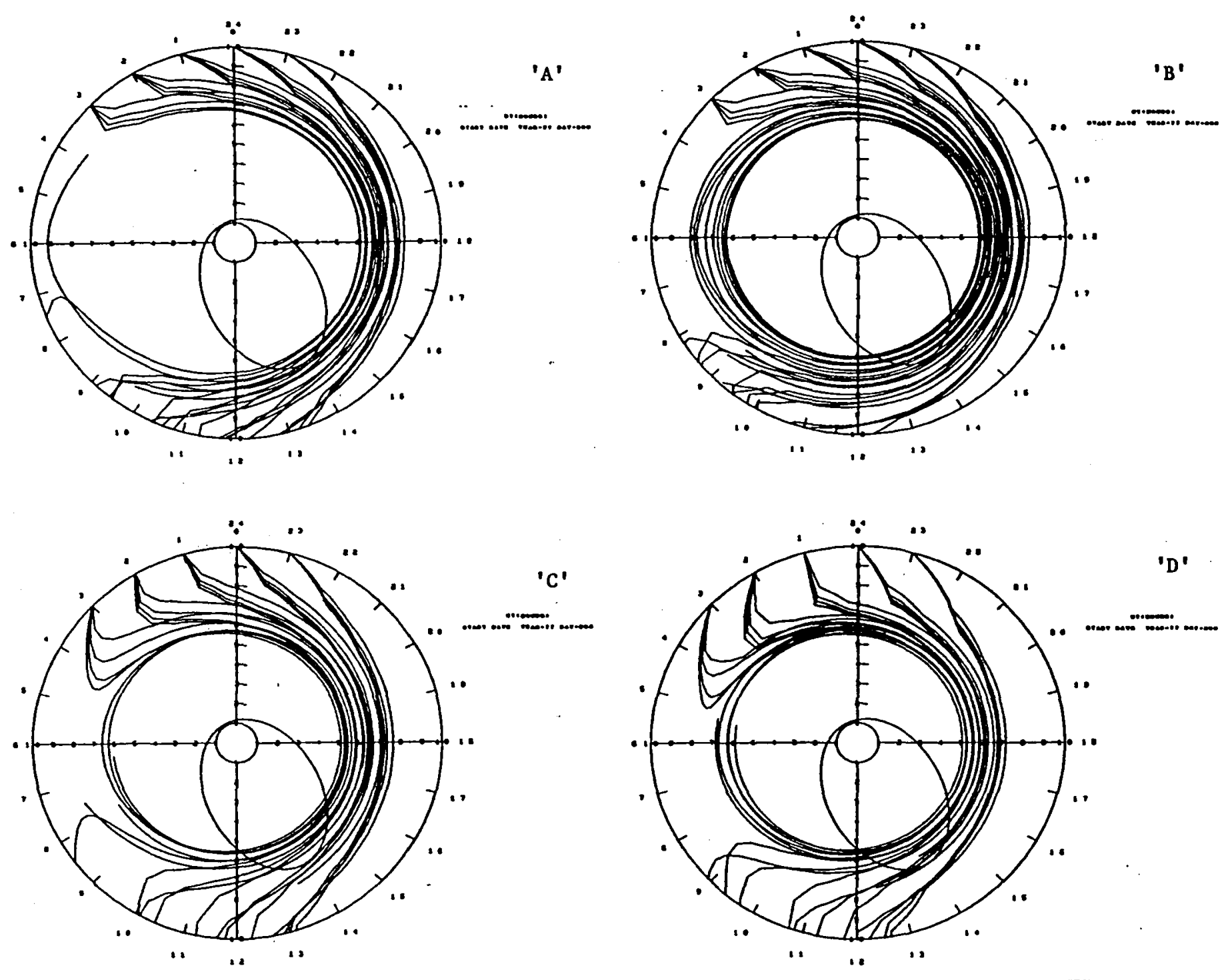

Fig. 19. Several time-dependent convection model trajectory plots (as described in the text) for high-energy protons on July 29, 1977. 
feature increased the trapping efficiency somewhat, but most trajectories from the midnight sector still remained untrapped.

Finally, in case $D$ the fleld gradient was maintained as in case $C$ but the convection electric field was increased by a factor of 2 in the radial range 7-10R $R_{E}$ and between 2000 LT and 0400 LT. This change drove particles more deeply into masnetosphere initially and thereby increased the trapping. (Again, the boundary between the increased and normal field is unphysical.) In summary, the time-dependent convection model can produce trapped drift trajectories for the higher energy proton component (>100 keV). The changes to the normal model in order to acconplish a large trapping ratio (such as changing the magnetic fleld gradient) appear quite consistent with observation and, thus, seem to provide reasonable physical improvements to the model. In most cases, it is seen that only high-energy protons injected near 0200-0300 LI are durably trapped. It is interesting that our proton drift-echo analyses al so tend to show injection positions near 0200 LT for the observed proton pulses in this substorm case (c.f. Figure 18). 
$-$

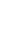

- 
III. DISCUSSION AND SUMMARY

In this paper we have used energetic particle and magnetic field data from six satellites near geostationary orbit to study an intense substorm period on July 29, 1977. Using these several spacecraft, well-distributed in local time, has given us a perspective on global substorm phenamenology not previously available. Several different analysis techniques (of which some are unique to energetic particles) were applied to the data sets and a self-consistent picture of the event period has emerged.

The following list sumarizes our observational results for the 1200 UT substorm at the three local times sampled:

Observations at $0300 \mathrm{LT}$

- Taillike magnetic field topology was seen prior to substorm onset.

- Large-scale boundary motion occurred as indicated by the flux dropout.

- Dropout boundary motion was to the inside and below observing spacecraft.

- Observing satellites remained in a finite flux region (high-latitude plasma sheet).

- In recovery from the dropout, the spacecraft were enveloped from below and inside.

- Two clear particle injections occurred (1200 and 1205 UT) with injection fronts extending as far east as 0300 UT.

- Injected particles clearly came rom outside and above S/C.

- High-energy proton drift-echoes were seen (injected at $\sim$ 0100-020n LT). 
- Weak $\mathrm{fux}$ decline was observed.

- only mildly taillike magnetic field stretching was seen.

- Energy-dispersed, injected electron population was observed: $1205-1220$ UT.

- Initial proton injection.spikes were only weakl y manifested.

- Proton drift-echo peaks were clearly seen (injected $\sim$ 0100-020n LT). Observations at 1300 LT

- Energy-dispersed, injected protons and electrons ( $E \geqslant 50 \mathrm{keV}$ ) were observed: 1205-1220 UT.

- Most low-energy (E \&50 keV) particle effects (1130-1300 UT) were adiabatic.

Based on the results presented here, some very firm conclusions regarding substorm phenomenology can be stated and these results can be extrapolated slightly to speculate on the missing pieces. First, there seems to be considerable evidence that the magnetosphere went through a period of substantial energy storage prior to the sudden energy release at $\sim 1200$ UT [McPherron, 1970, Baker et al., 1978]. An attractive and consistent interpretation is that this energy storage manifested itself as a tailike change of the magnetic topology at $6.6: \mathrm{R}_{E}$ before the substorm which in turn caused the observed flux dropout. The developing magnetic stress seemed: to relax slightly (1155-1200 UT) and then at 1200 UT It was suddenly relieved in the midnight sector simultaneous with the injection of the first pul se of hot plasma and energetic particles.

Our results al so show that the injected substorm particles came from outside (and above) the spacecraft at $s 0300$ LT. With the present 
information we are unable to tell from how far outside $6.6 \mathrm{R}_{E}$ the particles originated. Given the very stretched magnetic field topology that existed during the injection process, it is quite possible that the fleld lines carrying the injected particles actually extended deep into the plasma sheet (i.e. beyond $10 R_{E}$ ). One point that is clear is that there was only a very low level of energetic protons with $E>0.3 \mathrm{MeV}$ in the outer radiation zone before the substorm onset, and yet a large $\mathrm{fux}$ of such particles clearly appeared at geostationary orbit at substorm onset. Adiabatic modeling shows that trapping can be simulated by convection of high-energy particles from beyond $1 O R_{E}$.

Several recent papers have discussed the outer zone plasma injection process in terms of convection electric fields [cf. Kaye and Kivelson. 1979 and references therein]. These papers show that inward convection of plasma sheet particles associated with large-scale substorm electric fields can lead to substantial particle acceleration (as, indeed, was the case in the modeling represented in Figure 19). In this regard, however. K1velson [1980] has shown for the 1200 IT event discussed in this paper that acceleration of particles up to $q$ MeV cannot be done with the usual solar-wind imposed convection electric field.

Kivelson [1980] has argued that the substorm induction electric field may play an important role in the energization of the high-energy particles seen in this event. Using

$$
\frac{\Delta B}{\Delta t} \backsim 100 \quad r / 5 \mathrm{~min} \quad(\text { see Fig. 11) }
$$


Kivel son estimates (using $\nabla \times \vec{E}=-\frac{\partial \vec{B}}{\partial t}$ ) that

$$
\Delta \phi=\ell^{2} \Delta B / \Delta t \text {, }
$$

where $\Delta \phi$ is the change of electric potential and $\&$ is the scale of the region In which $B$ was collapsing. Assuming $\Delta \phi$ is of the order of $1 M V$ and $\Delta B / \Delta t \backsim 20$ $y / m i n$, gives $\& \sim 9 R_{E}$. Such a scale size for the region of near-tail collapse associated with the substorm seems reasonable and, thus, suggests that induction fields could account for the observed particles as geostationary orbit.

Based on large numbers of other high-energy proton events observed at synchronous orbit and in the plasma sheet. Baker et al. [1979] argued in favor of the importance of induction electric fields. They showed from the timing and duration of energetic proton events that particles with energies of $\backsim 1$ MeV cannot be produced by a small inward radial convection, say from $8-10$ $R_{E}$; large impulsive acceleration must be responsible for their production [e.g. Pellinen and Heikkila, 1978]. The high-energy proton results shown for this event are, therefore, consistent with the plasma sheet energization model presented by Baker et al. [1979].

In surmary, it seems evident that the multiple-spacecraft observational approach used here is a powerful one. Since the geostationary satellites that we have used in this paper have acquired literally. years of concurrent data, we look forward to many future joint studies of the effects of geomagnetic storms and substorms on magnetospheric energetic particle populations. 


\section{References}

Arnoldy, R. L., and K. W. Chan, Particle substorms observed at the geostationary orbit, J. Geophys. Res., 74, 5019, 1969.

Baker, D. N., P. R. Higbie, E. W. Hones, Jr., and R. D. Belian, High-resolution energetic particle measurements at $6.6 R_{E}, 3$, Low-energy electron anisotropies and short-term substorm predictions, J.Geophys. Res.. 83, 4863, 1978 .

Baker, D. N., R. D. Belian, P. R. Higbie, and E. W. Hones, Jr., High-energy magnetospheric protons and their dependence on geamagnetic and interplanetary conditions, J.Geophys. Res., 84, 7138, 1979.

Belian, R. D., D. N. Baker, P. R. Higbie, and E. W. Hones, Jr., High-resolution energetic particle measurements at $6.6 R_{E}, 2$, High-energy proton drift echoes,' J.Geophys. Res., 83, 4857, 1978.

Fennell, J. F., R. G. Johnson, D. T. Young, R. B. Torbert, and T. E. Moore, Plasma and electric field boundaries at high and low altitudes on july 29. 1977, J.Geophys. Res., to be published, 1981.

Fritz, T. A. and D. J. Williams, Osservations of multiple period waves on the magnetopause, paper 33B05, IAGA, XVII IUGG Gen. Assembly, Canberra, Aust.. 1979.

Kaye, S. M., and M. G. Kivelson, Time dependent convection electric fields and plasma injection, J.Geophys. Res., 84, 4183, 1979.

King, J. H., R. P. Lepping, and J.D. Sullivan, On the complex state of the interplanetary medium on July 29, 1977, J. Geophys. Res.. to be published, 1981.

Kivelson, M. G., Summary remarks on the July 29, 1977 event, EOS (Trans. AGU), 61. 335. 1980 . 
Manka, R. H., T. A. Fritz, R. G. Johnson, M. J. Teague, J. I. Vette, and R. A. Wolf, Overview of the July 29, 1977 substorm event, J.Geophys. Res.. to be publ1shed, 1981.

McPherron, R. L., Growth phase of magnetospheric substorms, J. Geophys. Res.. - 7ㅁ, 5592, 1970.

McPherron, R. L., Satellite studies of magnetospheric substorms on August 15 , 1968, 1. State of the magnetosphere, J.Geophys. Res., 78, 3044, 1973. McPherron, R. L., P. J. Coleman, Jr.. and R. C. Snare, ATS 6 UCLA fluxgate magnetaneter, IEEE Trans. Aerosp. Electron. Syst., 11, 1110, 1975.

Palmer, I. D., P. R. Higbie, and E. W. Hones, Jr.. Gradients of solar protons in the high-latitude magnetotail and the magnetospheric electric field. $\mathrm{J}$. Geophys. Res., 81, 562, 1976.

Pellinen, R. J., and W.J. Heikkila, Energization of charged particles to high energies by an induced substorm electric field within the magetota1l, 3. Geophys. Res., 83, 1544, 1978.

Schul z, M., and L. J. Lanzerotti, Particle Diffusion in the Radiation Belts, p. 40, Springer-Verlag, New York, 1974.

Smith, P. H., N. K. Bewtra, and R. A. Hoffman, Motions of charged particles, in the magnetosphere under the influence of a time-varying large scale convection electric field, Quantitative Modeling of Magnetospheric Processes, Geophys. Monograph, Vol. 21, (W.P. Ol son, ed.), AGU, Washington, D.C. 1979.

Walker, R. J., K. N. Frickson, R. L. Swanson, and J. R. Winckler, Substormassociated particle boundary motion at synchronous orbit, J.Geophys. Res.. 81, 5541, 1976. 
Wilken, B., D. N. Baker, P.R. Higbie, and T. A. Fritz, The SSC on July 29. 1977 and its propagation within the magnetosphere, J.Geophys. Res., to be publ1shed, 1981 .

Williams, D. J., T. A. Fritz, R. Wilken, and E. Keppler, An energetic particle perspective of the magnetopause, J.Geophys. Res.. 84, 6385, 1979. 
$-$ .

$-$ 
The Laboratory Operations of The Aerospace Corporation is conducting experImental and theoretical Invest1gations necessary for the evaluation and application of aclentiflc advances to new wlltary space systems. Versatility and flexibility have been developed to a high degree by the laboratory personnel in dealling with the many problems encountered in the nation's rapidiy developing space systems. Expertise in the latest sclentific developments is vital to the accomplishment of tasks related to these problems. The laboratories that contribute to this research are:

Aerophysics Laboratory: Launch vehicle and reentry aerodynamics and heat transfer, propulsion chemistry and fluld mechanics, structural mechanics, flight dynamics; high-temperature thermomechanics, gas kinetics and radiation; research in environmental chemistry and contamination; $c w$ and pulsed chemical laser development including chemlcal kinetics, spectroscopy, optical resonators and beam pointing, atmospheric propagation, laser effects and countermeasures.

Chemistry and Physics Laboratory: Atmospherlc chemical reactions, atwospheric optics, Ilght scattering, state-speciflc chemical reactions and radiation transport in rocket plumes, applied laser spectroscopy, laser chemlstry, batery electrochealstry, space vacuum and radiation effects on materials, lubrication and surface phenomena, thermionic emission, photosensitive materials and detectors, atomic frequency btandards, and bioenvironmental research and monitoring.

Electronics Research Laboratory: Microelectronics, GaAs low-nolse and power devices, semiconductor lasers, electromagnetic and optical propagation phenomena, quantum electron1cs, laser communications, 11dar, and electro-opt1cs; communication aciences, applied electronics, semiconductor crystal and device physics, radiometric 1maging; millimeter-wave and microwave technology.

Information Sclences Research Office: Program verffication, program translation, performance-sensitive system design, distributed architectures for opaceborne computers, fault-tolerant computer systems, artificial intelligence, and microelectronics applications.

Materials Sclences Laboratory: Development of new materials: metal matrix composites, polywers, and new forms of carbon; component fallure analysis and rellabllity; fracture mechanics and stress corrosion; evaluation of materials in space environment; materials performance in space transportation systems; analysis of systems vulnerability and survivability in enemy-induced environments.

Space Sclences Laboratory: Atwospheric and lonospheric physics, radiation from the atwosphere, density and composition of the upper atmosphere, aurorae and alrglow; magnetospheric physics, cosmlc rays, generation and propagation of plasma waves in the magnetosphere; solar physics, Infrared astronomy; the effects of nuclear explosions, magnetic storms, and solar activity on the earth's acmosphere, lonosphere, and magnetosphere; the effects of opt1cal, electromagnetic, and particulate radiations in space on space systems. 


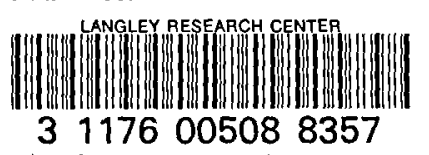

